\title{
Demystifying the Dark Side of Social Networking Sites through Mindfulness
}

\author{
Yusuf Hassan 1 \\ Institute of Management Technology (IMT) Business School Dubai \\ United Arab Emirates \\ yusuf@imt.ac.ae
}

Jatin Pandey

Indian Institute of Management (IIM) Indore

India

\section{Abstract}

Over the last few decades, social networking sites (SNS) have evolved as an effective medium of communication for the world. They are instrumental in connecting people across time and space with just a click. However, the darker side of SNS has resulted in a deteriorated human connection between individuals in real life. The current study is an attempt to examine the compulsive usage of SNS in detail. It utilizes a sequential mixed method design to examine the negative outcome of compulsive SNS usage and the effect of mindfulness in overcoming them. Findings of the study suggest that compulsive usage mediates the relationship between mindfulness and exhaustion; further, this relationship is moderated by extroversion personality traits.

Keywords: SNS, CSNS, sequential mixed method, mindfulness, extroversion.

\section{Introduction}

Every aspect of human technology has a dark side, including the bows and arrows.

Margaret Atwood

The advent of new technology is accompanied by a proclamation of the change that it will bring about. Information technology (IT) has been a boon to mankind for facilitating engagement across time and distance. It has the ability to digitally connect humans across different time zones with a simple click of a button. Undoubtedly, the coherent and enhanced effectiveness of IT is unmatchable. In fact, the general perception of IT is that it helps in increasing and strengthening our social ties. However, this is just one side of the complete story. While technology is certainly taking us places, its dependency and over-usage are also coming at a cost. Going back in history, the story of a human-like biological machine in a postapocalyptic Earth appeared in the late 1960s classic fiction work seems to have become a reality now. The merging of technology with our body has gone to such an extent that it has become too difficult to distinguish the biologically evolved identity with the one created by man-made technology. The dark side of technology is becoming more explicit in the form of a dystopia with deteriorating human connection between individuals in their real-life (Salanova, Llorens \& Cifre, 2013).

Today, over 1.95 billion people log in onto two major social media platforms, namely Facebook and Instagram daily. These 1.95 billion daily users comprise over $25 \%$ of the world's

\footnotetext{
${ }^{1}$ Both authors contributed equally to this paper, author listing is alphabetical based on last names.
} 
population, and they belong to different age groups and sections of our society (Kiberd, 2019). Furthermore, industry reports suggest that $27 \%$ of our time on the Internet is used for social media usage alone (Longstreet \& Brooks, 2017). Indeed, the much-appreciated IT in the form of social media platforms has entered almost everyone's private space. However, its entry in our personal space has also set the pendulum to swing the other way. Problems arising from excessive social media usage have become quite evident in our personal space. We can commonly see people hooked to their mobile phones and interacting with their friends on social networking sites (SNS) rather than interacting with them physically. People in the same room are found using their personal devices to engage with their neighbours in the virtual world (Lee, Noh \& Koo, 2013).

The growing concerns over the loss of our social interaction as a result of increased social media engagement and its long-term negative repercussions on our health and wellbeing have instigated debates in public forums. This reliance has also been accentuated by flexible knowledge-based work arrangements and technology driven aggregator models of business (Gupta, Pandey, Gaur \& Vohra, 2019; Pandey \& Sohani, 2020). According to the World Health Organization (WHO), over the last two decades, there has been a tremendous increase in social networking sites (SNS) usage, and undoubtedly, such usage had some clearly defined benefits to the users, including an enhanced awareness about health issues. However, at the same time, there have been several documented cases of excessive SNS use which has resulted in negative health consequences. In fact, for some countries of the world, the problem has reached the magnitude of a significant public health concern and requires immediate scholarly attention (WHO, 2018). The findings of the researchers and experts suggest that social media has become a persuasive form of technology that can modify certain parts of our psyche better than the real-world equivalent does (Singletary, 2020). We frequently fall prey to this feature of social media platforms (such as SNS) without realizing their long-term negative implications on our wellbeing. The prominent space occupied by social engagement in our real lives has now been substantially reduced as a result of our prolonged social engagement in virtual life. Instead of people consuming social media, at times, it appears that people are being consumed by social media (Slater, 2002).

\section{Limitations of the existing literature and contribution of the current study}

As discussed above, prolonged social media usage in the form of compulsive social networking site (CSNS) usage is resulting in weakening of our social fabrics. The physiological and psychological complications in the form of depression, fear of missing out (FOMO), psychiatric disorders, obesity, sleep deprivation, and others are already some of the major health and wellbeing related issues that have started surfacing as a result of CSNS (Dhir et al., 2018; Andreassen et al., 2016; Lee et al., 2014). There is also evidence indicating that in the long run, CSNS might also compromise the overall stability of our social institutions, such as family, economy, and education (Zheng \& Lee, 2016). Having said so, it is quite surprising that despite prior studies pointing towards the serious health and wellbeing related adverse implications of CSNS, scholarly research on CSNS still rests at a nascent stage (Dhir et al., 2018). In fact, the current literature on CSNS is overly focused on (Al-Yafi, El-Masri \& Tsai, 2018; Sharif, \& Khanekharab, 2017) marketing-related aspects of social media usage, such as the users' buying behaviour, or their service-related satisfaction and in-role work performance among others. This has resulted in ignoring the role of individual-level factors, such as the dispositional aspects (e.g., personality) in alleviating addictive technology behaviours (here CSNS usage). 
Studying these dispositional features in relation to CSNS is important because it will help us to understand the subjective meanings of such dispositional aspects on our daily enterprises. Further, it would help scholars and practitioners to design and formulate roles, training and rewards, keeping into consideration the unique role of personality on such compulsive behaviours.

Another major limitation of the existing research on CSNS is the absence of discussion on the role of context in social media usage. Contextualizing SNS or CSNS usage is important because it can highlight the greater role of a dynamic cultural, business, and political environment in shaping the influence of SNS on its users. Such insights not only hold relevance for researchers working in this domain, but also for the marketers who are looking for newer strategies to create a strong customer base through SNS. Over the last decade or so, the world has witnessed a gradual shift from the developed to developing economies in terms of the number of new SNS users joining social media platforms. To illustrate this, in India (an emerging market) alone, there are over 351.4 million people who used SNS in the year 2019 (Sanam, 2020). In fact, on an average, Indians spend over 2.4 hours a day on these sites. Even the monthly frequency of visits on Facebook for Indian users have crossed 1.6 billion views (Sanam, 2020). By contextualizing research on CSNS usage, we can highlight relevant behavioural and social manifestations associated with SNS users belonging to different social and cultural settings.

The current literature on CSNS also lacks a detailed discussion on the various outcomes of CSNS and potential strategies through which such prolonged social media engagement can be controlled or regulated. Some of the studies which have tried to explore these avenues to some extent have limited their scope to only the psychometric disorders, issues of self-esteem, or social anxiety (Apaolaza et al., 2019; Andreassen et al., 2016). What and how prolonged social media usage takes place and how it can be systematically regulated remains unanswered in these studies.

The motivation to do the current study is derived from the above gaps in the existing literature on compulsive social media usage, i.e., CSNS. Through the current study, the authors have tried to explore and examine the various factors that facilitate or impede CSNS usage in the first place and the subsequent negative effect of compulsive usage on the individuals. By doing so, the authors have tried to leave important theoretical and managerial implications relevant to the current scholarship on CSNS.

\subsection{Compulsive SNS Usage}

Compulsive SNS usage refers to the individuals' inability to manage or control the usage of Internet applications even though the usage of those specific Internet applications might affect them adversely (Fox \& Moreland, 2015). CSNS impacts the normal functioning of users and often results in severe problems, such as identity confusion, anxiety, and stress among others (Lai, Hsieh \& Zhang, 2019; Sharif \& Khanekharab, 2017; Turel \& Osatuyi, 2017; Apaolaza et al., 2019). The pertaining question here is, why do individuals engage in compulsive SNS in the first place? We observed inconsistency in the role of different factors that shape such behaviours among Internet users. For example, some researchers suggest that users feel a moral obligation to engage in such behaviour. They have often reported falling victim to conditions in which they lose track of time while using these sites and later complained of sleep deprivation, fatigue, dizziness, headache, and other problems (Ryan, Chester, Reece \& Xenos, 2014). Some other scholars argue that excessive involvement with SNS results from an expectation for certain rewards - both tangible and intangible ones (Turel \& Osatuyi, 2017). 
As we move deeper, moral obligations and expectations for rewards in the case of CSNS can be sourced from some of the psycho-social aspects of our lives, i.e., the dispositional, sociocultural, and reinforcing behavioural aspects of our daily enterprise (Andreassen, 2015). Different scholars have highlighted how one or many of these aspects are responsible for shaping and promoting CSNS behaviour (McIntyre, Wiener \& Saliba, 2015; Kim, LaRose \& Peng, 2009). The current study suggests that those individuals who are externally-oriented are expected to be inclined towards the utility of Internet for the instrumental purpose (Andreassen et al., 2013). However, individuals who had a less satisfying life were found associating themselves more with digital platforms (e.g., social networking sites, etc.). Further, such associations were not for instrumental purposes, instead of to fulfill the social voids in their lives.

Similarly, the socio-cultural aspects, such as peer pressure, family orientation, and role modelling have also been thought to shape our attitude and behaviour towards social media. Social comparison intensifies the degree of usage by creating continuous pressure on users (Bandura, 1986; Andreassen, 2015). Users' attitude, behaviour, and their intentions can significantly vary based on the groups they are affiliated to (Fishbein \& Ajzen, 1997). How strongly such affiliation (ex. Family, friend circle, professional groups, etc.) is influencing their decisions would determine their intentions and subsequently, the intensity to use SNS (Baker \& White, 2010).

Finally, reinforcing behaviour can also be one of the determinants for CSNS (Meerkerk et al., 2010). Reinforcing behaviour includes an expectation for rewards. The reward here includes both tangible and intangible ones. We can explain reinforcing behaviours using the learning theories. Popularity on social networking sites encourages users to repeat behaviours, including aggressive use of SNS. Similarly, the absence of any appraisal, fear of missing out, and others may result in reduced SNS usage. In the case of compulsive SNS usage, expectations for positive outcomes, such as rewards may motivate users to engage in spending over time (Moxley, 1992; Ryan et al., 2014; Andreassen, 2015).

Based on the above discussion on CSNS, we may demystify or conclude that there exists an inconsistency in the roles different factors play in shaping such behaviours among the SNS users. Therefore, it is worth exploring the factors that foster and impede CSNS in order to gain more clarity on this topic. We were motivated to explore the following research questions to address existing gaps in the literature on SNS. First, what are the outcomes of compulsive SNS usage, and how can it be controlled? We also wish to know if the relationship is affected by individual dispositional factors or not.

\section{Methodology}

The current study utilizes a sequential mixed method design to examine the various factors that foster and impedes CSNS. Sequential mixed-method refers to the approach of collecting, analysing, and integrating quantitative as well as qualitative data during the research process within a single study (Pernkopf, Latzke \& Mayrhofer, 2020; Arora \& Stoner, 2009; Morse \& Niehaus, 2009; Hancock, 2007). The objective of the sequential mixed method research designs is to provide a detailed understanding of the problems that we are trying to examine (Ivankova, Creswell \& Stick, 2006). When both quantitative and qualitative approaches are combined and used together in one study, it gives the researcher an opportunity to utilize the strengths of both the approaches through robust analysis. Mixed methods have been 
recognized for their true practical and outcome-oriented approach of inquiry (Cameron, 2009). For the purpose of the current study, we followed the recommendations of Janice Morse for mixed-method research (Tashakkori \& Teddlie, 2010).

Our research has adopted an exploratory sequential mixed method design, as suggested by Morse and other scholars. Accordingly, first, we followed an explorative approach using qualitative interviews to decipher the antecedents and outcomes of CSNS. Subsequently, in study II, we adopted a quantitative research design using the survey method to validate the findings of the first study. The advantage of using a qualitative-quantitative mixed method design for studies, such as the current one is multifold. First, this approach has been followed in prior studies on similar research problems in the domain of information and technology research (Srivastava \& Chandra, 2018; Li, Worch, Zhou \& Aguiton, 2015; Mao, 2014). Second, an explorative study in the form of qualitative research at the beginning helps in setting the ground to explore why and how a phenomenon occurs. This forms an essential step towards theory building, especially when the topic is unexplored. Later, a quantitative study that follows the explorative research helps in attaining the generalizability or explaining the causality identified through the exploration of the research problems (Berman, 2017; Creswell, 2003). Finally, an exploratory sequential mixed method offers voice to the participants and ensures that the findings of such studies are grounded in the participants' experiences. Since the current study is about users' prolonged engagement with social media platforms (which is one of their daily experiences), this method was not only suitable but also met the desired level of rigour.

\section{Study I}

\subsection{Method}

The main objective of study-I was to explore the outcomes of compulsive SNS usage and how such compulsive usage can be regulated or controlled. The very exploratory nature of our research question encouraged us to use a qualitative research design in the first place (Kumar, Sachan \& Mukherjee, 2017; Tashakkori \& Teddlie, 2010). Scholars have discussed the ability of qualitative explorative research designs in deciphering the complexity of socio-technical interactions in our lives (von Hellens, Beekhuyzen \& Kerr, 2006). Qualitative studies have the ability to explore the novices of a phenomenon and explain the underlying motivations for the occurrence of such phenomenon or behaviour (Throuvala et al., 2019). In other words, qualitative research design in information technology research can offer important insights into the development, adoption, and usage of technology. Exclusive research on SNS and qualitative research designs have proved very effective in identifying and examining similar relationships (Ding, 2019; Divine et al., 2019).

\subsection{Sampling}

Data for study-I was collected through semi-structured interviews conducted over a span of three months. We followed a two-step inclusion and exclusion criteria to identify and interview our respondents. At the first stage, we randomly choose people and asked them to share their frequency of social media usage. Some of the preliminary questions which were asked to these random respondents were: "Do you have an account on any social networking sites?", If yes, "Which social networking sites have you used in the past or use at present?" and "On an average, how often do you use these social networking sites in a week?" A total of 21 respondents were interviewed in the first round. Based on their preliminary responses, 
participants who reported high usage of SNS were invited for the main interview, i.e., the second round of interaction (Cao et al., 2018; Ellison, Vitak, Steinfield, Gray, \& Lampe, 2011). In order to restrict the number of respondents to be interviewed in the second round, we followed the theoretical sampling approach (Draucker, 2007). In the theoretical sampling approach, the sample size is determined based on the evolving theory and not by a predetermined population dimension. We engaged our respondents through multiple rounds of interviews; their responses were transcribed and coded under major themes. Wherever required, we even went back to the field for more data. Respondents were given the freedom to choose the location and timing for their interviews to make them comfortable. Distantly located participants were interviewed through telephone and Skype. Interviews began with an ice-breaking session followed by responses against the research-related queries. The above approach followed by us in the second round is consistent with other studies which suggested that the interview and the analysis process should be done simultaneously (Langley, 1999). We continued the process of data collection and themes generation until we started receiving repetitive responses from our sample against the research questions. Based on the saturation of themes, the sample size for our study was finalized at 15 . Out of the 15 respondents, 8 were male respondents, whereas the rest of the 7 participants were women. The minimum educational qualification of our respondents was an undergraduate degree, and the highest qualification was doctorate. The mean age of the respondents was 26 years.

\subsection{Analysis}

All the interviews were recorded with the prior consent of our respondents. Recordings were transcribed, and a copy of the verbatim transcript was also shared with the respondents in order to allow them to suggest changes (if any). Once, all the interviews were transcribed, the authors checked for reliability by measuring the inter-rater reliability (Kappa value). The Kappa value was above 0.76, which was consistent with the recommendation made in prior studies (MacPhail et al., 2016; McHugh, 2012). For the purpose of analysing our responses, we used the Gioia method, which is a variant of grounded theory (Gioia, Corley, \& Hamilton, 2013). Grounded theory approach has been used in information technology (including issues on social media) research in the past, and hence it was deemed suitable for the current study (Wiesche et al., 2017). Gioia's method has been mentioned for its "qualitative rigour" without compromising the creativity and revelatory nature of such studies (Gioia, Corley, \& Hamilton, 2013). Extending the learning from grounded theory, the Gioia method considers that apart from the fact that reality is socially constructed, the researcher is also a knowledge agent. It argues that researchers are aware of their objectives of the research and they can explain the thoughts, intentions, and actions involved in the process of creating a socially constructed reality (Gioia, Corley, \& Hamilton, 2013).

The Gioia method involves creating themes at three levels. The first order represents the voice of the informants and the process of developing the first-order themes is similar to axial coding (Strauss \& Corbin, 1998). First-order themes are refined into second-order themes in which the theoretical realm turns more precise and clear. Finally, the third-order aggregate dimensions reflect the "distillation" of the second-order constructs (Gioia, Corley, \& Hamilton, 2013). Based on the analysis of the responses, we developed the three orders of themes, and the same has been represented through Figure 1, $2 \& 3$. 


\subsection{Findings}

Many of the antecedents and consequences of CSNS were in line with the findings of previous studies. However, the following demanded detailed inspection.

\subsubsection{Mindfulness as speed-breaker for CSNS}

It was found that people who were mindful of their actions were less prone to CSNS usage (see Figure 1). As can be seen from the following response by a respondent to a question on why he thinks his usage of social media is regulated.

I am always aware of how much time I spend on Facebook or Instagram. I keep track of the usage and when I don't find it meaningful, I log out.

The above narrative provides an indication of the respondent's ability to control one's behaviour. While accessing the Internet, the respondent remains aware of his continuous SNS usage and analyses his situation. When he perceives that such a situation is becoming less meaningful, he puts on hold his actions to prevent further escalation in his perception. We received similar responses from some other participants as well. For example, one respondent expressed:

I have disabled real-time notification from social networking sites. Frequent notifications can cause distraction. So to control this, I log in to my account only during a particular time of the day and use it for not more than five or six minutes.

While the first narrative focused on the "what and why" of the intensity of SNS usage, the second narrative illustrates the "how" of regulating SNS usage. In order to prevent any disturbance or distraction from SNS, the respondent has disabled the notifications on his mobile phone. He is not only aware of the strategies to control his involvement with social media, but he is equally motivated and capable of bringing those strategies into practice. Mindfulness is able to reduce the physiological consequences of stress that could have been caused due to the distraction caused by SNS and reinstate it by a positive enhancing effect (Jain et al., 2007).

The inability to address distractions like the one mentioned in the narratives above, may disturb the maladaptive practices and cause stress, anxiety, and fatigue. In the case of respondents who were not mindful of their activities, we observed an excessive usage of SNS. For example, a respondent shared:

...I know it would sound like an addiction, but stay too engrossed in Facebook and Instagram. Especially during my weekends, I spend hours scrolling news and posts uploaded on these platforms.

The respondent in the above narrative is aware of the fact that the excessive use of SNS is leading her towards an addiction, yet is unable to control this maladaptive practice. The respondent did not mention the reason for not being able to control her behaviour which suggests that such behaviours are occurring away from a conscious and self-regulating self. Mindfulness increases self-esteem and reduces anxiety (Apaolaza et al., 2019). Both self-esteem and reduced anxiety are critical for self-regulation and focus (Rhodewalt \& Tragakis, 2003). In the above narrative, low mindfulness seems to weaken self-esteem and increases anxiety to debilitate any action against uncontrolled automated behaviour (Apaolaza et al., 2019). 


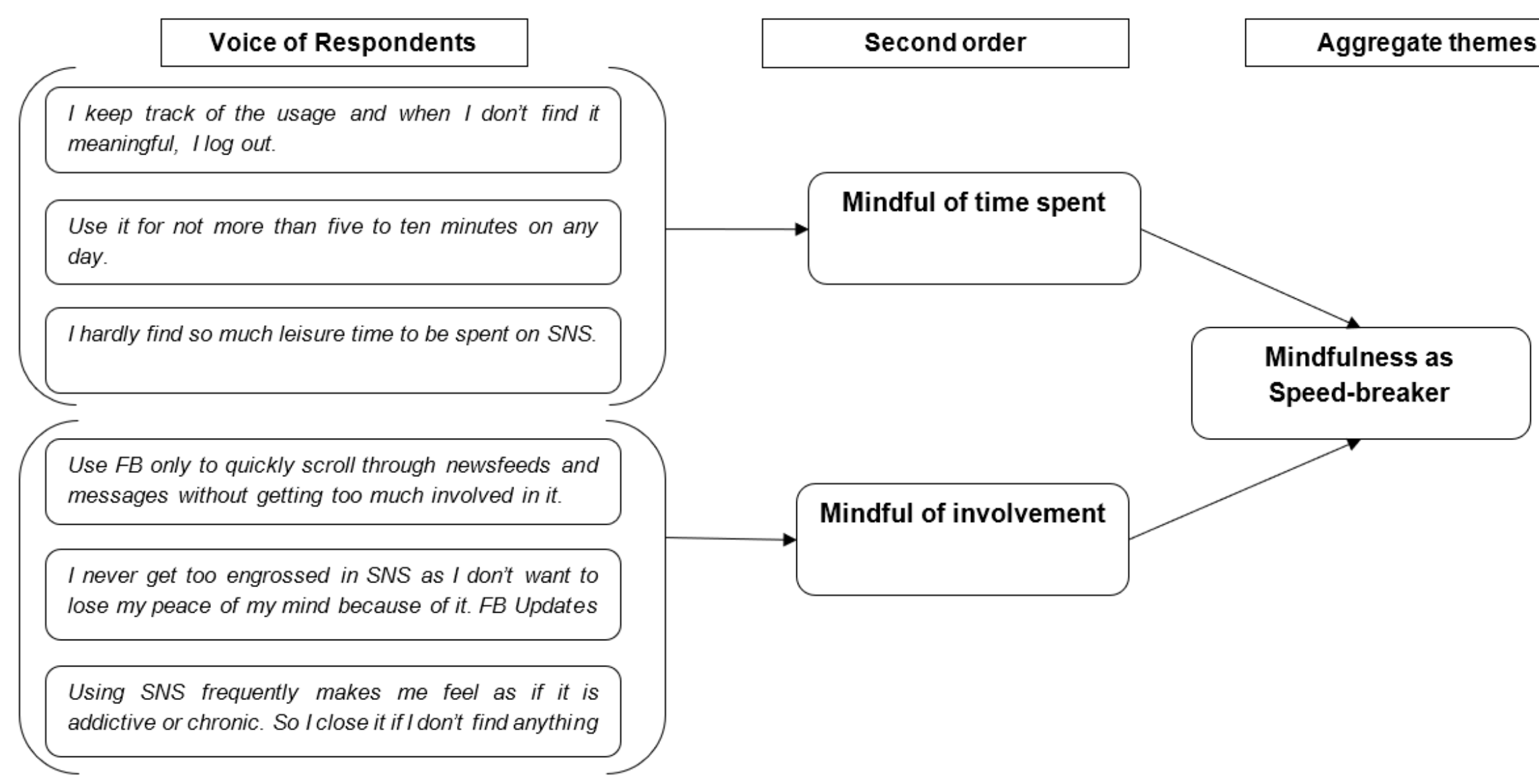

Figure 1: Mindfulness as speed-breaker. 


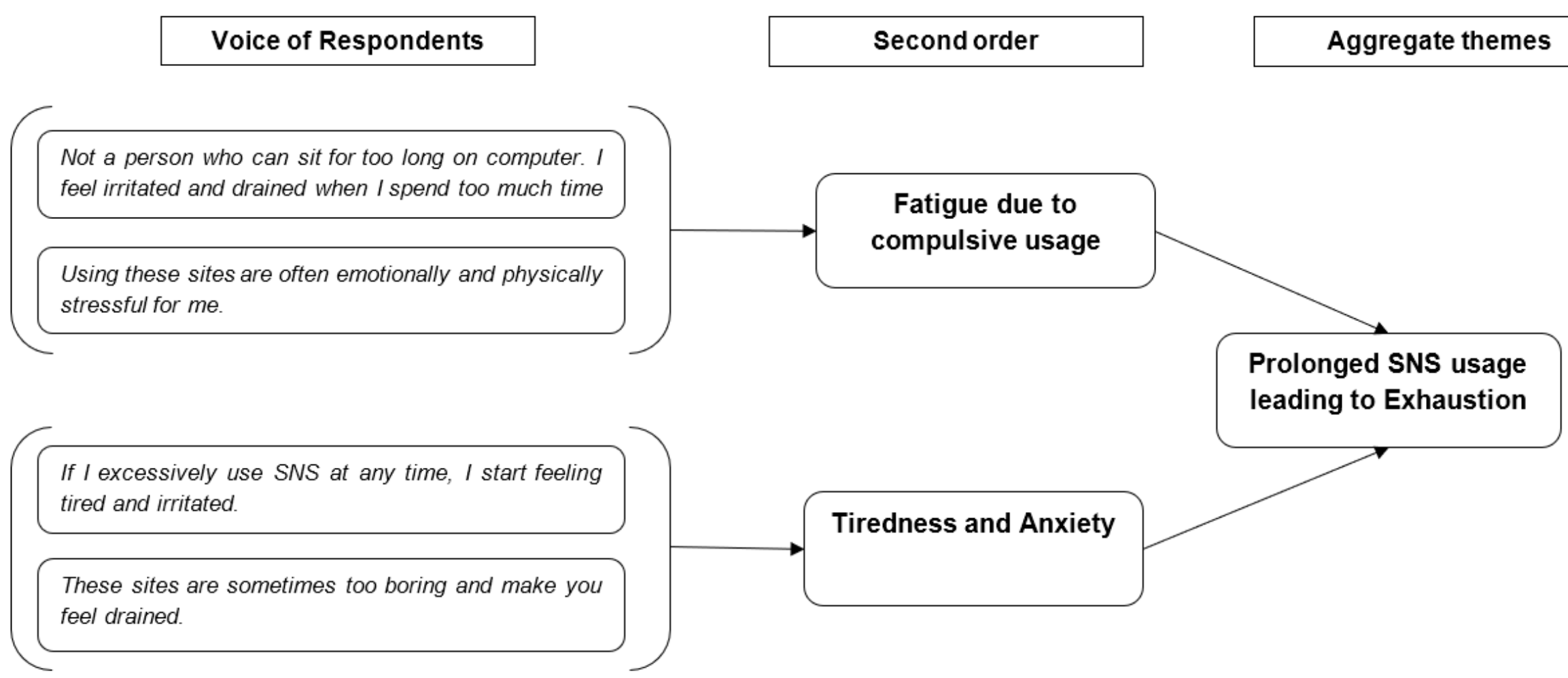

Figure 2: Prolonged SNS usage leading to exhaustion. 
The following narrative further illustrates the lack of mindfulness and automated behaviour.

It happens at sudden times, I chat with people on FB, and such conversation often goes for hours. We human are not robots that suddenly you will stop using FB because you follow any daily routine for such usage. So I don't stick to any set duration of time for social media. After my office, I log in to FB and use it for two hours or so.

\subsubsection{Prolonged SNS usage leads to exhaustion}

Respondents expressed that their prolonged engagement with social networking sites results in some form of anxiety, stress, and tiredness (see Figure 2). For example, one of the respondents who extensively use Facebook and Instagram explained:

After using Facebook and Instagram for long, I feel strain in my eyes and headache. I often have a feeling of tiredness and stress. This has happened to me quite often.

Similarly, another respondent who is employed as a digital marketer and uses social networking sites for marketing related works said:

..When I have to keep using FB (Facebook) or Twitter every now and then for my work, I feel exhausted and drained.

The two narratives mentioned above illustrate the psychological effect of excessive use of SNS by the respondents. Strain in eyes, headache, sleep deprivation, somatic issues, etc. are some of the major symptoms of exhaustion (Wiegner, Hange, Björkelund \& Ahlborg, 2015). Both the respondents had earlier mentioned about the time when they first started using Facebook. Since this time period was reasonably large (10 years and 4.5 years respectively), we may assume that continuous accumulation of SNS-induced stress resulted in these health-related problems among the respondents.

\section{The effect of extroversion}

We also asked respondents questions regarding their likes and dislikes, gauged their preference for sociability and gregariousness in both the real and virtual world. It was found that people who considered themselves extroverts were more prone to CSNS usage and exhaustion (see Figure 3). For example, one of the respondents reported:

I like experiencing new things in my life. I love going out and planning trips with friends and relatives. I often use social networking sites to find like-minded people with whom I can plan such trips.

In the above narrative, the respondent seems to enjoy the company of others. He actively engages in activities that include like-minded people for healthy interaction with them. The respondent is showing characteristics of extroverts who in general are known for spending more time with people and have a large social network. They presume themselves as more effective and find pleasure in engaging in various aspects of life (Watson \& Clark, 1997). 


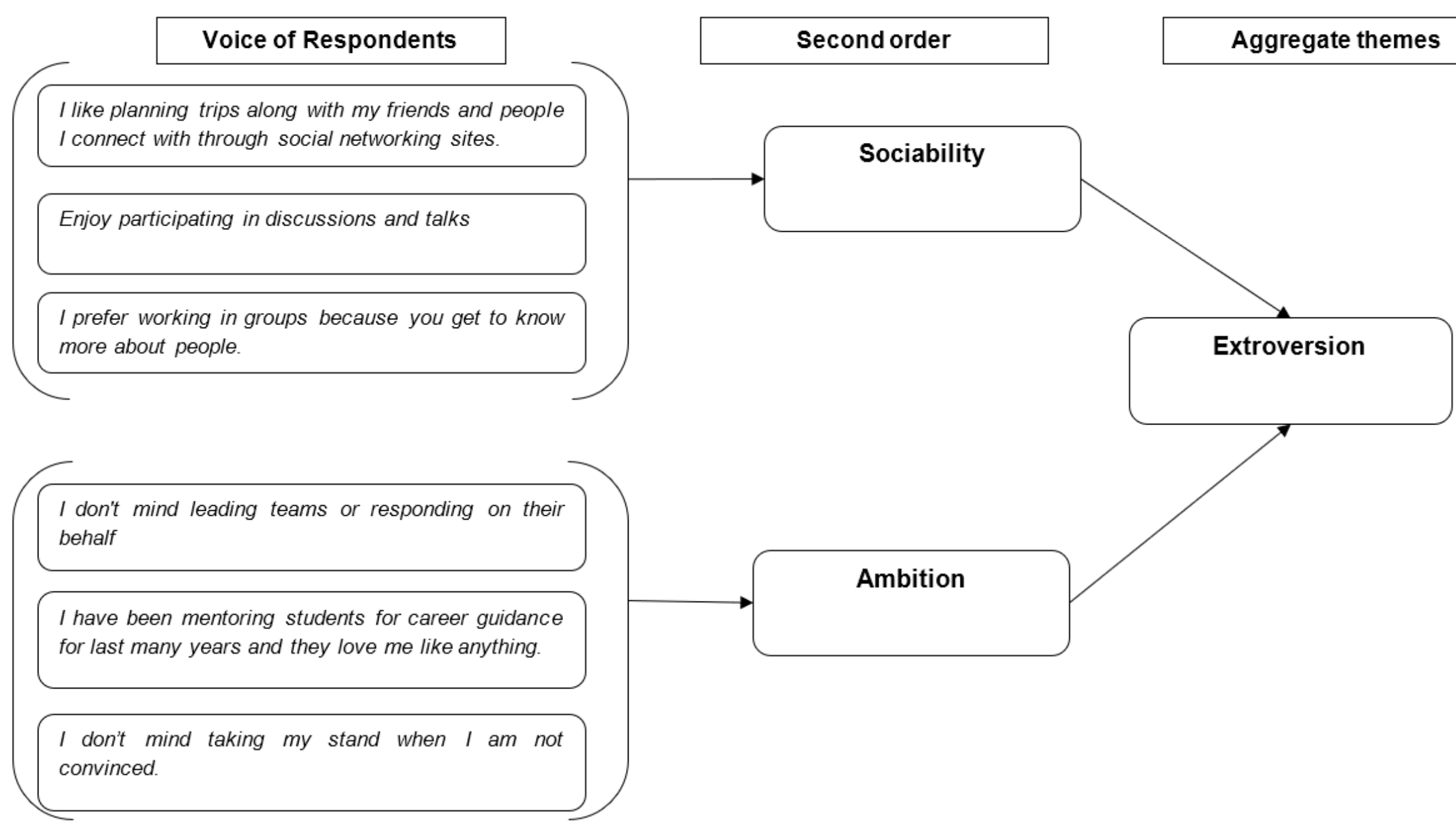

Figure 3: Extroversion trait. 
But often such enthusiasm to meet new people and socialize or find new avenues for adventure results in tiredness. When a further inquiry was made, the same respondent expressed how socializing taking place on SNS causes his exhaustion. The respondent said:

I like to interact with people, and I can do so easily using my social media accounts; obviously! Social networking sites have helped me connect with my old friends and colleagues, but after spending too much time on FB and others, I feel tired and it appears as if I have done some manual work.

The findings of study I identified extroversion, exhaustion, and mindfulness as three major constructs associated with SNS exhaustion. While mindfulness regulated social media usage and thus exhaustion, extroversion seems to promote SNS usage among the respondents. How these variables interact with each other needs further probing through a review of the literature and statistical modelling. Therefore, study II first examines the existing literature on these constructs before framing the hypothesis for analysis.

Findings of study I also identified some association between CSNS and exhaustion. The literature on exhaustion conceptualizes it as a "chronic state of physical and emotional depletion that results from excessive and continuous hassles of any form" (Wright \& Cropanzano, 1998, p. 486). Exhaustion can, therefore, result in the feeling of psychological and emotional draining. Since CSNS usage is the prolonged and excessive use of social media, it is expected that such continuous engagement should equally result in physical and emotional depletion of our resources, and hence result in exhaustion.

After completing study I, we felt a strong need to validate our findings to ensure that the emergent model developed through study I is generalizable and holds true for population other than the one taken as a sample in study I. Therefore, we conducted study II. As stated, this study extends the above arguments based on the review of relevant literature to propose and test the hypothesized model. The approach is also consistent with the recommendation of scholars who suggested a review of the literature and statistical modelling post an inductive study in a sequential mixed method research design (Gioia, Corley, \& Hamilton, 2013; Tashakkori \& Teddlie, 2010).

\section{Study II}

We start with a brief review of the literature on the constructs uncovered in study II, followed by the hypothesis generation. The process of hypothesis development was done in two stages. First we adopted a comprehensive review process to examine prior literature on the constructs. This stage was followed by hypothesis building and data collection.

\subsection{Mindfulness}

Our understanding of mindfulness has roots in the Theravāda Buddhist doctrine, and its contemporary meanings are the offshoots of the popular Burmese Buddhist reform movement that took place in the early twentieth century (Sharf, 2015). Buddhist literature has defined mindfulness as a "clear and single-minded awareness of what actually happens to us and in us at the successive moments of perception" (NyanaponikaThera, 1972, p.32). However, the popular definition of the concept assumes it as a "state of being attentive to and aware of what is taking place in the present" (Brown \& Ryan, 2003, p. 822). Over the last few decades, the concept has drawn serious attention from scholars owing to its positive relationship with the wellbeing of individuals (Brown \& Ryan, 2003; Rybak, 2013; Shonin et al., 2016). 
Organizational studies have emphasized the role of leaders' mindfulness on employee satisfaction, absenteeism, and in-role performance (Reb et al., 2009).

Similarly, studies on training and development have highlighted its role in stress management (De Vibe et al., 2013), improving cognitive abilities (Chiesa, Calati \& Serretti, 2011) and athletic performance (Aherne, Moran \& Lonsdale, 2011). Thus, the role of mindfulness in improving our life is imperative. However, a large portion of the research on mindfulness in the past has concentrated on mindfulness and its role in mitigating issues in real life. But, how virtual social life is shaped by our awareness and ability to control behaviour, i.e., mindfulness? Is something that remains ill-examined. The current study is an attempt to fill this research gap.

\subsection{SNS exhaustion}

SNS exhaustion is defined as the "degree to which the users believe that their resources, such as time and effort are depleted by the usage of social networking platforms" (Han, 2018, p. 123). Engaging with virtual social network platforms, such as Facebook, Twitter, and others, involve several benefits, obligations, and challenges at the same time. For example, one aspect of SNS usage is that the individuals are expected to dedicate time and energy to create profiles and share information with others. The purpose is to build a virtual identity of the users. However, the darker side of social networking through online platforms expect users to continuously engage and respond to their virtual social contacts in order to mark their presence and justify their worth (Zhao, Grasmuck \& Martin, 2008; Han, 2018). Frequent use of SNS by the users creates a perception that any reduced commitment or reduced participation in SNS would result in loss of social contacts in users' real lives (Beyens, Frison \& Eggermont, 2016). This may result in fear, which could cause stress and oblige the users to further engage with such platforms. Repeated compulsive SNS usage finally causes depletion of our physical and psychological resources, i.e., exhaustion (Marder et al., 2016). Some studies (Bright, Kleiser \& Grau, 2015; Han, 2018) have suggested that such SNS-induced exhaustion may also result from different features of a social networking site. These may include chat options, photo and video sharing applications, opinion and polling, and other features. Privacy concerns and overloading of information are the major cause of SNS exhaustion. The way SNS usage would impact an individual and result in exhaustion may vary from one individual to another (Lo, 2019; Mount et al., 1999).

Undoubtedly, research on exhaustion has become relevant in the contemporary world. Psychological and physiological strain in the form of exhaustion is resulting in anxiety and depression among individuals (Bint-E-Rashid \& Irfan, 2018). SNS exhaustion is associated with the stress-induced by digital platforms. The relevance of SNS exhaustion rests with the fact that most of the social interactions today take place over digital platforms, such as Facebook, Twitter, Instagram, and others.

\subsection{Extroversion}

Extroversion is one of the big-five personality traits. Extroversion is characterized by distinct engagement with the external world (Friedman \& Schustack, 2016). Extroverted individuals tend to be more assertive, talkative, sociable, and active. They showcase high group visibility. This is unlike those who are low on extroversion and are more reserved, retiring, and cautious (Roccas, Sagiv, Schwartz \& Knafo, 2002). Hogan suggested that extroversion comprises two dimensions, namely, ambition and sociability. The assertive nature of extroverts facilitates goals achievement through demonstration of competences in accordance with our social standards (Hogan, 1986). This sociability is facilitated in the virtual world by engaging with social network sites. 
An extroversion personality trait is capable of shaping some important behaviours among individuals. For example, in organizational settings, it can influence the performance, engagement, and other positive outcomes associated with the workforce. Similarly, in our community settings, the trait can significantly moderate the degree of our personal adjustment to ageing and other issues (Costa Jr, McCrae \& Norris, 1981). Before we draw our assumptions about the positive aspects of extroversion, it is important to remember that the dispositional factors are not always desirable. Their role in shaping our behaviour either positively or negatively depends on how they act upon us (John, 2018). To illustrate this, recent studies found that if manifested at a very high level, extroversion may result in maladaptive practices (McCord, Joseph \& Grijalva, 2014). The same organizational setting in which low or moderate extroversion could result in high performance; self-aggrandizement, long-windedness, and egotistic nature associated with high extroversion may result in low performance and customer dissatisfaction (Coker, Samuel \& Widiger, 2002). Similarly, studies on addiction indicated that extroversion might promote addiction towards a particular behaviour or activity, such as excessive mobile usage in some cases (Cook, Griffiths \& Pontes, 2018; Cho, Kim \& Park, 2017).

Extroversion becomes a relevant construct for our study because examining this trait in the context of the virtual world would help us understand how this trait behaves differently on the virtual social interactions compared to its influence on those taking place in our real world.

\section{Theory and hypothesis}

As we have discussed earlier, mindfulness is "our ability to bring complete attention to the experiences occurring in the present moment" (Charoensukmongkol, 2016, p.12). The literature on mindfulness argues that open and creative attention to one's experience or environment helps to equip oneself better to let these experiences come and go without affecting ones' life (Leroy et al., 2013; Reb, Narayanan \& Chaturvedi, 2012).

Several benefits can be attributed to mindfulness. For example, mindfulness can significantly address the problematic, i.e., maladaptive use of the Internet (Calvete, Gamez-Guadix \& Cortazar, 2017). Similarly, healthcare studies (Fraumeni-McBride, 2019; Spears et al., 2017) have applauded mindfulness for its critical role in addressing addiction-related treatments. Given the benefits associated with mindfulness, the authors argue that mindfulness should significantly reduce compulsive SNS usage among individuals.

Compulsive SNS behaviour has become very common today. Research suggests that such compulsive usages are resulting in acute mental disorders among 5-8\% of the global population (Shonin, Van Gordon \& Griffiths, 2013). Excessive usage of SNS through mobile phones or computers is believed to result in prolonged stress which may cause mental disorders (Creswell, 2017; Pantic, 2014). Mindfulness can significantly mitigate these issues. In an experimental study, Weinstein, Brown \& Ryan (2009) found that mindfulness can help significantly in coping with stressful situations. Respondents who reported high on mindfulness were more motivated to cope with stress compared to the other respondents. The underlying mechanism is that mindfulness increases our confidence to regulate stress instead of getting anxious.

The role of mindfulness in managing late positive potential (LPP), a neural marker responsible for emotional regulation has also been recognized in some studies (Brown, Goodman \& Inzlicht, 2013; Bean, 2018). These studies have supported the argument that high mindfulness is effective in regulating emotions, and thus imbibing individuals with the ability to control 
or regulate their behaviour. Since, social networking platforms, such as Facebook, Twitter, etc., are an integral part of social media, we may expect mindful persons to better regulate the intensity of their SNS usage in order to deal with any negative or maladaptive consequences associated with such excessive use.

Theoretically, the relationship between mindfulness and SNS usage can be explained using the conservation of resource (COR) theory (Hobfoll \& Shirom, 2000). The theory proposes that individuals have the ability to selectively choose behaviours that can maximize their returns and minimize their losses. Individuals seek to conserve their resources. In the case of SNS, the users are expected to reduce the frequency of their SNS usage when such behaviours are resulting in stressful conditions (Zhang et al., 2011). Mindful individuals are able to recognize SNS usage behaviours as merely an activity that can be regulated or controlled. The confidence and effort to overcome such behaviour reduces anxiety associated with CSNS (Apaolaza et al., 2019). At any moment, an individual may have multiple responses available for a stimulus. Bishop et al. (2004) stated that mindfulness helps in conserving our personal resources by directing our attention to only those responses which can maximize benefits (instrumental learning) and reduce losses (i.e., stress).

Based on the above discussion, we would like to propose our first hypothesis,

\section{H1: Mindfulness is negatively associated with compulsive SNS usage}

Extending our discussion further, excessive usage of SNS results in negative consequences, such as SNS exhaustion (Luqman et al., 2020; Masood et al., 2020). Since mindfulness helps in vitality and self-regulation of personal resources, mindful individuals are aware of their self and the situation in which they act. This consciousness guides them to step back and decide from further engaging in the current activity in order to reduce the impact of stress; SNS usage is a stress-inducing activity. Further, mindfulness offers stress-mitigating mechanisms which are more reflective in nature as compared to the absent-mindedness, which encourages reactive exacerbating responses against a stimulus (Reb, Narayanan \& Ho, 2015). Thus, it would be appropriate to say that mindfulness is even capable of reducing stress-related outcomes, such as exhaustion.

From the COR theory perspective, mindfulness is an effective mechanism that can prevent the depletion of personal resources, such as values, energy, states, and conditions. In the real world, mindful individuals have a preference for problem-focused coping mechanisms over emotion-focused coping strategies to handle stress (Charoensukmongkol, 2013). They are engaging in a more optimistic problem analysis and planning process instead of stagnant deliberation. Any discouraging negative emotions and unhealthy efforts to escape the condition are discouraged by them (Charoensukmongkol, 2013). We may expect a similar response from mindful individuals toward technology-induced exhaustion, i.e., SNS exhaustion. Therefore, we propose our second hypothesis which is,

\section{H2: Mindfulness is negatively associated with SNS exhaustion.}

Summarizing our discussion above, we have pointed out how mindfulness can regulate our engagement with SNS. We also highlighted the existence of prolonged stress, i.e., SNS exhaustion resulting from compulsive SNS usage. We now argue that the compulsive SNS usage will mediate the relationship between mindfulness and SNS exhaustion. Our argument is theoretically grounded on the SSO perspective and some empirical studies. Schumer \& Buchwald (2012) noted that the frequency of SNS usage is critical for work-related stress. It cautioned us regarding the observations that SNS usage often results in a loss of our 
interactions and social ties in the real world. Individuals who frequently engage with SNS lose interest in meeting and interacting with people in real life and they may even turn prone to issues, such as concentration issues due to frequent distractions (Junco, 2012; Charoensukmongkol, 2016). However, in the case of individuals high on mindfulness, it is relatively easier to evaluate and then control the actions through the cognitive emotion regulation strategies (Karing \& Beelmann, 2019). Thus, mindful individuals are able to even regulate the intensity of SNS use and subsequent outcomes (e.g., exhaustion) associated with such usage. In both cases, the intensity of SNS usage is decisive. High/low mindfulness reduce/increase compulsive SNS usage, and thus reduce/increase SNS exhaustion.

The association between compulsive SNS and exhaustion can be explained theoretically using the Stressor-Strain-Outcome perspective (SSO perspective). The SSO perspective has been used in prior studies to examine the implications of technological features as environmental technology stimuli on the virtual experiences of users (Cao et al., 2018; Ayyagari, Grover \& Purvis, 2011). The framework suggests that our ability to manage the demand for environmental stimuli determines how well we avoid or cope up with technology-induced stress and subsequent strain. Notably, the stressor here refers to any environmental stimulus "that appears annoying, irksome, or disruptive to SNS users" (Cao et al., 2018, p.3). When the demand for such technological-environmental stimulus exceeds our ability, it results in a chain of psycho-physiological reactions that eventually cause exhaustion (Jonsdottir et al., 2013; Koeske \& Koeske, 1993).

Extending this discussion further, the second aspect (the first being mindfulness and CSNS) of the proposed mediating relationship, i.e., the relationship between mindfulness and emotional exhaustion has been established through some empirical studies (Broderick, 2005; Kiken \& Shook, 2011; Kiken \& Shook, 2012). These studies have argued that mindfulness increases self-efficacy, optimism, and self-esteem that aid in reducing emotional exhaustion to a great extent. Since SNS exhaustion is one of the forms of emotional exhaustion caused due to prolonged usage of social network platforms, mindfulness should also significantly reduce SNS exhaustion. Therefore, we propose,

\section{H3: Compulsive SNS usage mediates the relationship between mindfulness and exhaustion}

The way mindfulness, compulsive SNS usage, and SNS exhaustion interact with each other vary significantly from one individual to another. Research advocates forgiving dispositional factors due to the consideration in predicting the behaviour of individuals in one's day-to-day life (Witt et al., 2002; Giluk, 2009). Individual differences (trait-based) affect the degree of motivation that promotes or impedes the use of personal resources (such as energy, vigour, enthusiasm) in order to overcome the psychological strains (Penney et al., 2011). Personality traits may determine our behaviours and actions through different approaches. For example, individuals with different dominant traits may have different choices of self-selecting highly stressful/less stressful activities (Garden, 1989). Furthermore, some of the personality traits may predispose individuals to experience stress more intensely compared to others. Finally, traits may determine the coping mechanism and its effectiveness for different individuals (Armon, Shirom \& Melamed, 2012). Surprisingly, studies on personality, mindfulness, and exhaustion are limited, and more empirical research is needed to investigate the relationship among these variables.

Among the big five personality traits, the relationship between extroversion and mindfulness is quite presumptuous. Extroverts or individuals high on extroversion are socially gregarious; they are more open to interact and share their thoughts and views with others (Giluk, 2009). 
However, a major challenge associated with this kind of personality is their tendency to crave more excitement, adventure, and stimulation most part of their life (Dollinger, 1993; Costa Jr \& McCrae, 2008). As a result, extroverts tend to resist being both mindful and socially outgoing at the same time (Winning \& Boag, 2015). We believe that a similar role of extroversion should be observed in the case of online engagements. Hence, we may assume that extroversion may moderate the intensity of mindfulness on CSNS usage and exhaustion to an extent. For individuals high on extroversion, the effect of mindfulness would get suppressed as a result of the dominant nature of the personality trait. Contradictory to this, where extroversion is low, mindfulness would dominate the behaviour of such individuals. Based on these arguments, we propose our fourth hypothesis:

H4: Extroversion has a significant moderating effect on the relationship between mindfulness and compulsive SNS usage.

The effect of personality traits such as extroversion not only affects mindfulness but also its relationship with other constructs such as SNS usage and SNS exhaustion. As stated earlier, personality traits determine how individuals would avoid or cope with the stressors. Prolonged usage of social network sites results in stress, and mindfulness helps in overcoming these stressors. Here extroversion can moderate the role of mindfulness on SNS exhaustion because extroverts are generally talkative and sociable (Kiffin-Petersen, Jordan, \& Soutar, 2011). Similar arguments can be put forth in the case of interactions happening in the virtual world.

The relationship between CSNS, SNS exhaustion, and personality traits, such as extroversion are expected to encourage users to engage with SNS on a frequent and prolonged basis as these platforms offer a wide opportunity to interact and socialize. Socializing and interactive nature are among the core characteristics of extroversion in the real world. It is not surprising if similar tendencies are observed in the case of the virtual world. The moderating role of extroversion in the relationship between CSNS and SNS exhaustion can also be established based on some of the field studies on extroversion, which has observed that such traits promote prolonged social media usage (Klobas et al., 2018; De Cock et al., 2014).

Based on the above discussion, Hypothesis 5 and 6 have been proposed:

H5: Extroversion has a significant moderating effect on the relationship between mindfulness and exhaustion.

H6: Extroversion has a significant moderating effect on the relationship between compulsive SNS usage and exhaustion.

Based on the literature review and discussion above, we may summarize our understanding through a hypothesized model given in Figure 4. 


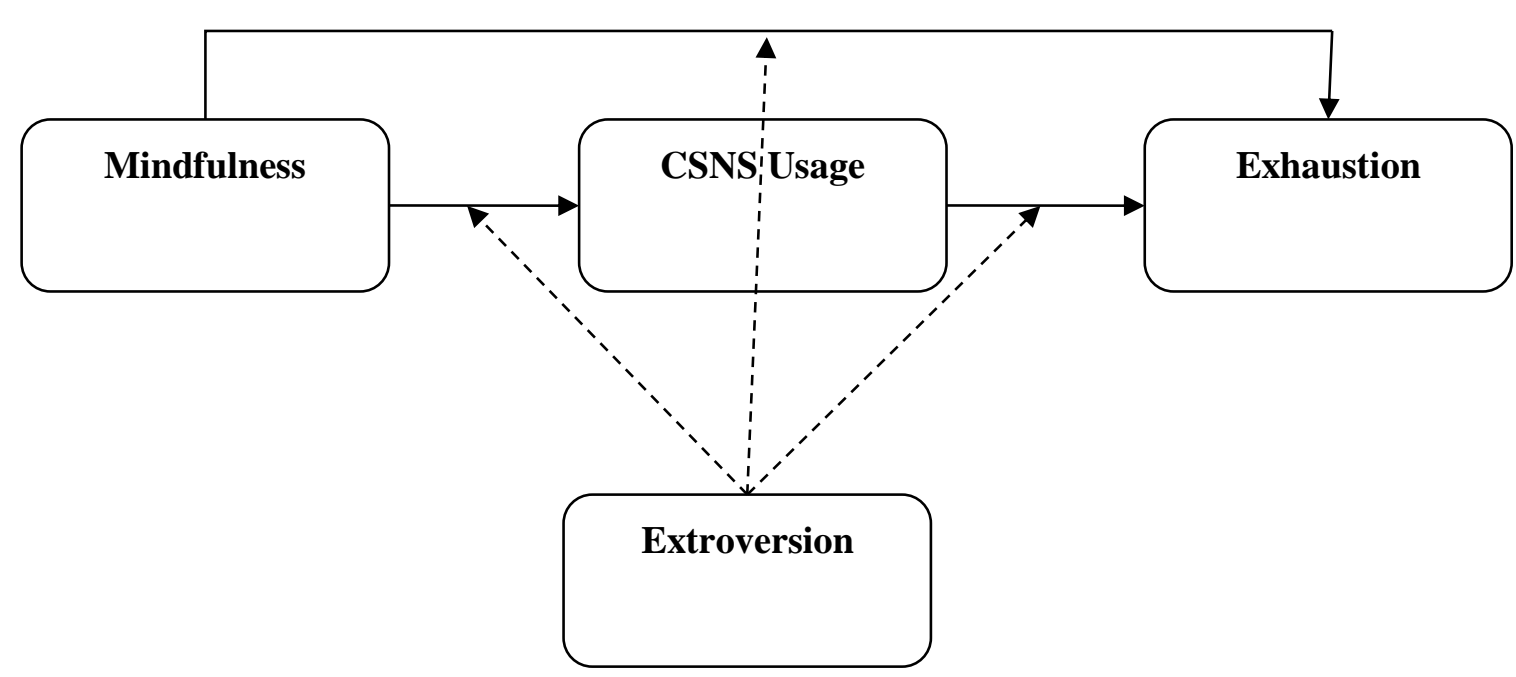

Figure 4 Hypothesized Model

\section{Methodology}

Data for study II was collected using the survey method. For the purpose of collecting data, we followed the purposive sampling technique. The main objective of using purposive sampling is to ensure that our sample is logically assumed to be representative of the desired population we are trying to examine (Lavrakas, 2008). The purposive technique is also considered suitable for mixed-method research designs, such as the one used in the current research (Palinkas et al., 2015). Finally, prior research on similar topics has used purposive sampling to collect responses for their study, and hence the technique became our first choice for the current study (Longstreet \& Brooks, 2017; Nalwa \& Anand, 2003). The desired population in our study were the active SNS users of different age groups and gender. Therefore, we purposely sent the online survey forms to only those respondents who were reportedly active SNS users at that point in time. The questionnaires were sent to 350 SNS users belonging to different age groups, educational, and professional backgrounds. Out of the 350 respondents who were emailed, we received survey forms from 249 respondents. However, 13 of these 249 forms were either incomplete or redundant, and hence they were not included in the final sample. Finally, a total of 236 valid responses were used for analysis. For the purpose of measuring the constructs, we used established scales which had previously been used in other empirical studies. The questionnaire prepared for the study was shared with ten respondents (other than those 236 in the main sample) and three subject-matter experts for validity.

\section{Measures}

We measured the constructs using established scales (Appendix 1). Compulsive SNS usage was measured using a scale developed by Turel \& Osatuyi (2017). Sample items included: "I spent time on social networking sites even though I had other deadlines." The Cronbach's alpha for the scale was 0.65. Response for mindfulness was measured by Baer et al. 's (2006) trait mindfulness scale. The sample item includes the following: "It seems I am running on automatic without much awareness of what I am doing". The Cronbach's alpha for the scale was 0.83 . Similarly, SNS exhaustion was measured using a scale proposed by Han (2018). The scale has been used in other similar studies too. The sample item of this scale includes "I feel exhausted 
by using social networking sites." The Cronbach's alpha for the scale was 0.73. Finally, extroversion was measured by Gosling et al. 's (2003) scale. The sample item for extroversion includes the following: "I see myself as extraverted, enthusiastic." The Cronbach's alpha for the scale was 0.91. We also measured Social desirability using Crowne \& Marlowe (1960) 's social desirability scale. The sample item for social desirability include: "I am always polite even to people who are offensive." The Cronbach's alpha for this scale was 0.5 .

All the responses for the questionnaire were recorded using a 7-point Likert scale ranging from 1, which stood for strongly disagree to 7, which stood for strongly agree.

We followed the two-step approach to analyse the data. Initially, we used confirmatory factor analysis to establish convergent and discriminant validity using SEM followed by the second step using PROCESS macro (model 59) to test the overall model. The bootstrap samples were 2000 and the confidence interval was 90. Bootstrapping is a statistical procedure that resamples a single dataset to create many simulated samples in order to provide more robust results. Exhaustion was the dependent variable; mindfulness was the independent variable, and compulsive usage was the mediator. Extroversion was the moderator. Age, gender, education, work experience, and social desirability were controlled.

We conducted Herman's single factor test and found that a single factor accounted for less than 50 percent variance. In addition, marker variable analysis (Williams, Hartman \& Cavazotte, 2010) was also done to identify common method bias. We found that the inclusion of the marker variable did not substantially change the item factor loadings indicating that the common method variance is not substantial.

\section{Findings}

Table 3 shows the mean, standard deviation, and bivariate correlations.

\begin{tabular}{|c|c|c|c|c|c|c|c|}
\hline & Mean & SD & Exhaustion & Mindfulness & $\begin{array}{c}\text { Compulsive } \\
\text { Use }\end{array}$ & Extraversion & Age \\
\hline Exhaustion & 3.68 & 1.40 & 0.76 & & & & \\
\hline Mindfulness & 4.73 & 1.36 & $-.305^{* * *}$ & 0.93 & & & \\
\hline $\begin{array}{l}\text { Compulsive } \\
\text { Use }\end{array}$ & 3.89 & 1.19 & $-.508^{* * *}$ & $.327^{* * *}$ & 0.83 & & \\
\hline Extraversion & 4.13 & 1.45 & $-.168^{* *}$ & $.118^{*}$ & $.177^{* *}$ & 0.6 & \\
\hline Age & 26.76 & 8.30 & $.118^{*}$ & -.027 & $-.164^{* *}$ & .038 & \\
\hline
\end{tabular}

Table-3: Descriptive statistics and bivariate correlations

Table 4 shows the following,

Convergent validity: The Cronbach's alpha and Composite Reliability (CR) of all variables are above 0.6 , thus indicating convergent validity (Taber, 2008). The average variance extracted values of all variables except compulsive use is above 0.5. AVE value; below 0.5 is considered acceptable if factor loading and composite reliability is well established (Fornell \& Larcker, 1981). Recent studies such as Lam (2012) have considered AVE value below 0.5 for the purpose of their analysis. 
Discriminant validity: MSV < AVE and the Square root of AVE greater than inter-construct correlations, thus indicating discriminant validity.

\begin{tabular}{lcccccccc}
\hline & CR & AVE & MSV & MaxR(H) & Exhaustion & Mindfulness & Compulsive & Extraversion \\
\hline Exhaustion & 0.767 & 0.529 & 0.130 & 0.796 & $\mathbf{0 . 7 2 7}$ & & & \\
Mindfulness & 0.929 & 0.686 & 0.342 & 0.932 & -0.361 & $\mathbf{0 . 8 2 8}$ & & \\
Compulsive & 0.833 & 0.425 & 0.342 & 0.870 & 0.346 & -0.585 & $\mathbf{0 . 6 5 2}$ & \\
SNS Usage & & & & & & & \\
Extraversion & 0.873 & 0.821 & 0.048 & 1.568 & -0.130 & 0.172 & -0.219 & $\mathbf{0 . 9 0 6}$ \\
\hline
\end{tabular}

Note: $\mathrm{N}=236$

Square root of AVE on the diagonals

Table 4: Validity Table

Table 5 shows the output of the hierarchical regression analysis. Mindfulness was negatively and significantly associated with compulsive use $(b=-0.426, p<0.001)$, thus supporting hypothesis 1 . Mindfulness was negatively and significantly associated with exhaustion $(b=-$ $0.23, p<0.001$ ), thus supporting hypothesis 2 . The conditional indirect effect of mindfulness on exhaustion via compulsive usage is negative and significant at medium (extroversion=mean value; beta=-0.1, Boot SE 0.04, 90\%CI [-0.176,-0.038]) and high (extroversion=plus 1 SD above the mean; Beta=-0.16, Boot SE 0.06, 90\%CI [-0.279,-0.070]) values of extroversion, thus supporting hypothesis 3 .

\begin{tabular}{lcc}
\hline \multicolumn{1}{c}{ Variables } & CSNS Usage & Exhaustion \\
\hline CSNS Usage & & $0.24^{* *}$ \\
Mindfulness & $-0.42^{* * *}$ & $-0.23^{* * *}$ \\
Extraversion & $0.09^{*}$ & 0.06 \\
Mindfulness X Extraversion & $0.06^{*}$ & $0.11^{* *}$ \\
CSNS UsageX Extraversion & & -0.06 \\
Control Variables & & \\
Age & $-0.04^{* *}$ & -0.01 \\
Edu & -0.05 & -0.01 \\
Work Experience & 0.01 & 0.01 \\
Social Desirability & 0.05 & -0.02 \\
F & $14.15^{* * *}$ & $5.75^{* * *}$ \\
R2 & 0.3 & 0.19 \\
\hline Note N=236; $+p<0.1 *^{*} p<0.05 ; * * 001 *^{* * *} p<0.001$.
\end{tabular}

Note: $\mathrm{N}=236 ; \mathrm{tp}<0.1 ;{ }^{*} \mathrm{p}<0.05 ;{ }^{* *} \mathrm{p}<0.01 ;{ }^{* * *} \mathrm{p}<0.001$.

Table 5: Results of moderated mediation model.

The interaction term of mindfulness and extroversion was significantly associated with compulsive use $(b=-0.057, p<0.1)$, thus supporting hypothesis 4 . The interaction was examined using a graph presented in Figure 5. The figure shows that the negative relationship between mindfulness and compulsive use is stronger for people scoring high on extroversion. 


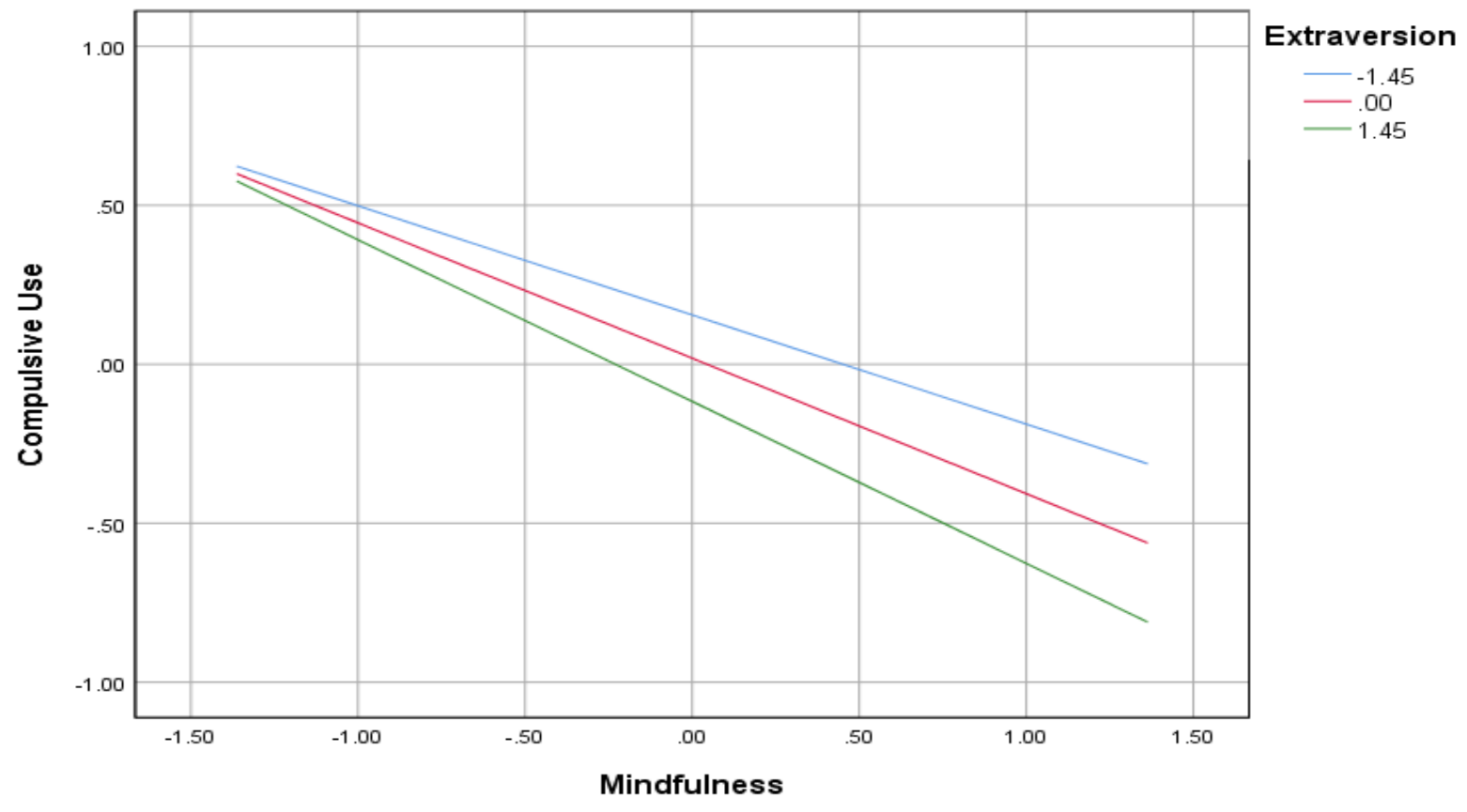

Figure 5: Graphical representation of the interaction between mindfulness and CSNS

The interaction term of mindfulness and extroversion was significantly associated with exhaustion $(b=-0.114, p<0.05)$, thus supporting hypothesis 5 . The interaction was examined using a graph presented in Figure 6. The figure shows that the negative relationship between mindfulness and exhaustion is stronger for people scoring high on extroversion. The interaction term of compulsive SNS use and extroversion was not significantly associated with exhaustion, thus hypothesis 6 was not supported.

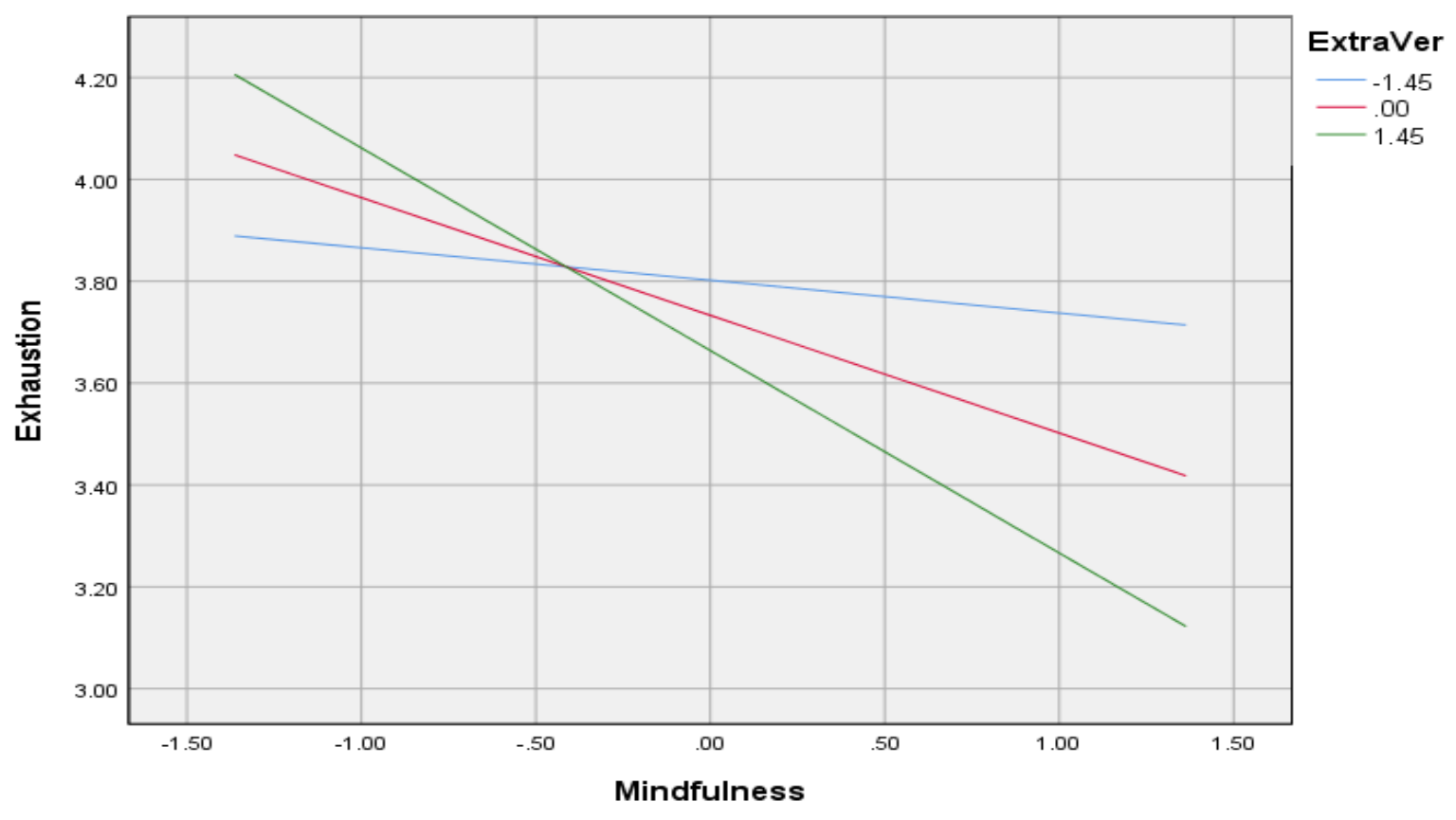

Figure 6: Graphical representation of the interaction between mindfulness and exhaustion. 


\section{Discussion}

Over the last few years, compulsive SNS usage has drawn the attention of scholars and practitioners due to an increased number of SNS subscribers on the one hand, and the serious physical and mental health issues associated with such usage on the other hand. Prior studies have offered some indicators to distinguish CSNS usage from other forms of SNS usage. For example, LaRose, Lin \& Eastin (2003) identified it with deficient self-regulation. Similarly, Caplan (2010) explained CSNS usage as an unsuccessful attempt to cut down and control SNS usage. However, in all these studies, the factors that facilitate or impede CSNS usage have been largely ignored. Examining these variables is important because such findings might help scholars and practitioners in addressing various psychological and physiological issues concerning CSNS usage. The current study is an attempt to address the gaps in the existing literature on SNS.

Findings of study I and II can be synthesized here. Our findings suggest that the excessive use of social media in the form of CSNS usage is interlinked to dispositional factors, such as personality traits and mindfulness. Our study indicates that mindful persons are less impacted by SNS usage. One reason for this could be the fact that such people are more capable of effectively regulating their behaviour in order to avoid depletion of their personal resources (e.g., energy and enthusiasm). Observing and acting with awareness forms two decisive aspects of mindfulness. People reporting high on mindfulness are able to reflect on their behaviour based on the observations, and it subsequently encourages them to control such behaviours that could otherwise have resulted in adverse consequences (Turel \& Osatuyi, 2017). In the case of SNS usage, mindful persons are aware of the negative consequences (e.g., exhaustion) resulting from excessive SNS use. They are able to effectively balance the social pressure and self-desire that promotes such high usage of SNS.

The literature on mindfulness suggests that mindful persons are capable of balancing pressures of various kinds. They assume external forces, such as peer pressure, as a transient and are equipped to handle such pressure through an obligatory and less-automatic approach towards social media (Turel \& Osatuyi, 2017; Sanger \& Dorjee, 2016; Sriwilai \& Charoensukmongkol, 2016). Therefore, while engaging with social media platforms, they keep a check on the instrumentality involved in such engagements, and they clearly identify the tipping point at which they have to take a break.

Our study also extends the discussion on mindfulness by taking into account the role of moderators-extroversion in our engagement with digital platforms. It was observed that mindfulness was less effective in addressing CSNS usage among users who reported high on extroversion traits. The above findings validate the observations by scholars extroversion is characterized by high gregariousness and interactive tendencies. Extroverts prefer engaging in community activities, socializing, and networking. Social networking sites appear to be an effective platform for expanding ones' personal network and relationship. Therefore, extroverts are seen increasingly engaged with SNS as it serves this purpose in the digital world (Kim, Hsu \& de Zuniga, 2013). Compared to other personality types, prolonged SNS usage is high among extroverts. Such prolonged usage leaves open doors for obsession or addiction. Our study indicates that mindfulness works only when extroversion is low or moderate among SNS users. In the case of users high on extroversion, mindfulness becomes less imperative in controlling the excessive usage of social media as the influence of extroversion trait supersedes the effect of mindfulness. On account of this, the user starts experiencing stress and subsequently, SNS-related exhaustion (Nawaz et al., 2018). 
We also examined the moderating role of extroversion in the relationship between CSNS and exhaustion. Exhaustion is the loss of our physiological and mental strength. Such losses can significantly impact our engagement and overall performance (Dhir et al., 2018). The current study suggests that personality traits are detrimental in the way CSNS leads to exhaustion among social media users (Liu \& Ma, 2018). Literature suggests that SNS users are prone to techno-stressors which are "technology-induced stimuli, events, or demands" (Cao, Masood, Luqman, \& Ali, 2018, p.7). When users frequently use social media, the stressors cause strain, and subsequently, the users feel exhausted (Cao et al., 2018; Charoensukmongkol, Moqbel \& Gutierrez-Wirsching, 2017; Bright, Kleiser \& Grau, 2015). Empirically findings of study II show that in the case of users reporting high on extroversion, exhaustion due to CSNS usage is higher compared to those who reported low on extroversion. In other words, the gregarious and interactive nature of extroverts further enhances the strength of the CSNS-Exhaustion relationship. The above findings have some important theoretical and managerial implications which have been discussed in the subsequent sections.

\section{Contribution and Implications}

\subsection{Theoretical implications}

Research on SNS has primarily focused on the positive role of social networking sites. For example, studies have highlighted its role in connecting non-profit organizations with donors and fundraisers across the globe (Waters, Burnett, Lamm \& Lucas, 2009). But, the darker side of SNS has remained largely ignored (Cao et al., 2018). Our study contributes towards this gap in the literature by highlighting the aetiology of CSNS, which has several important negative implications, exhaustion being one of them. A major theoretical contribution of this study is extending the current scholarship on Conservation of Resource theory. COR insinuates that in situations when we face a threat of losing our personal resources and opportunities to gain new resources are missing, then we try to maintain or preserve our existing current resources (Hobfoll \& Shirom, 2000). COR theory provides an effective theoretical grounding to understand our findings. It assumes that the individual would discontinue indulging in such behaviours, which could result in the depletion of our personal resources (Zhang et al., 2019). It is important to understand that the resources here refer to the values, energies, objects, and state of mind (Hobfoll, 1988). In the current study, the behaviour is synonymous with compulsive SNS usage, whereas personal resource is vigour, and the loss of it is resulting in SNS exhaustion. Our study extends the discussion on COR theory by accounting for dispositional factors that were originally not included in the COR framework. Based on our findings of the two studies, we argue that the conservation of resources is not just governed by the rate at which resources are depleted. Instead, the conservation process is a very complex phenomenon that involves both the rate at which resources are lost and the personality-related dispositional factors, and it determines how the individual would respond to such challenges. We further argue that the openness, talkative, and interactive nature of the individuals weakens our control such that the depletion of personal resources (such as SNS usage) are quicker among extroverts as compared to individuals with any other personality traits.

The current study also extends the discussion on the SSO perspective. While the SSO perspective explains how stress and stressors result in negative outcomes, such as exhaustion; the framework does not elaborate on the antecedents and moderators of such psychophysiological reactions. Our findings provide mindfulness and CSNS usage as the two 
major antecedents of exhaustion. Further, it also highlights the greater role of personality traits in moderating the chain reaction, which has been discussed in the SSO framework.

\subsection{Managerial implications}

Our study also offers some important managerial implications. Our study indicates the necessity for designing and developing a more comprehensive training program for compulsive SNS usage. Social media are effective in disseminating information and entertaining users. However, its excessive usage may equally result in negative outcomes, such as dissatisfaction, isolation from the real world, and mental health disorders, among others (Apaolaza, Hartmann, D'Souza \& Gilsanz, 2019). We believe that if customized training for mindfulness is offered, taking into consideration the dispositional factors, such as the personality-related individual differences, then such training can effectively address the negative outcomes of SNS usage to a great extent. Recently, an article published in the Washington Post mentioned the term "digital detox," which is basically a strategy to reduce the amount of time we spend on social media platforms (Griffiths \& Kuss, 2018). Digital detox could be both voluntary as well as involuntary depending upon who regulates our digital engagement at home or our workplace. The article recommends strict rules to be placed by the employers to control CSNS behaviour among the employees and a similar approach for academic institutions to be followed. The findings of our study hold an important place for firms working in the field of digital marketing. A large number of companies are focusing on the promotion of their brands through social networking sites. This invariably, means employees would be spending a large part of their daily office time on these platforms to contribute towards the business. Such employees are susceptible to poor wellbeing, which could invariably impact their performance. Such organizations would require holding special training to improve employees' mindfulness in order to cope up with such issues. Further, such organizations are also expected to provide flexible work schedules to reduce their employees' discomfort with prolonged internet usage.

The current study also holds important practical relevance for adolescents and youths who are increasingly being attracted to social media usage. As the Japanese psychologist, Tamaki Saitō said, the world has been predominantly occupied by Hikikomori, a generation that has traded their social lives for Internet, media consumption, and video-games (Kiberd, 2019). Our study suggests that we may restrict social media from consuming our healthy life through a planned intervention in the form of appropriate training to control our actions (Turel, Mouttapa \& Donato, 2015).

\section{Limitations and Future Research Directions}

The current research has some limitations which can be addressed in future studies. Based on the findings of study I, we identified that exhaustion is as an important outcome of compulsive SNS usage. However, our study had limited its scope of research to the context of India. Similar studies with a cross-cultural sample can explore and examine other relevant outcomes.

Second, the limitation of the current study is that it does not focus on the differences in CSNS usage by individuals based on factors such as the age, gender, type of the sector in which the respondent is employed, and prior education, among others.

Another limitation of the current study is that it focuses only on one dispositional trait, i.e., extroversion. Possibility of findings other individual-level factors in future studies cannot be denied. Finally, mindfulness as a concept has been distinguished from similar constructs such 
as emotional intelligence, wakefulness, and various forms of self-awareness. For example, emotional intelligence (EI) refers to the ability to monitor emotions (of self and others), and use it as a guiding force to direct ones' action. But, EI represents only one stage of mindfulness, i.e., when mindfulness is high. However, in a state of less mindfulness, emotions occur outside the realm of our knowledge. Awareness of our current behaviour is acknowledged much later (Brown \& Ryan, 2003). Similarly, wakefulness is another construct that is worth discussing here. Wakefulness is different from mindfulness because the former concerns cognitive tasks, which are operationalized based on some external environment, and there are possibilities for multiple perspectives for the same operationalized tasks (Bodner \& Langer, 2001; Brown \& Ryan, 2003). One example of wakefulness is the functional diversity within business organizations. Langer \& Moldoveanu (2000) noted that even though different employees are assigned functionally diverse roles in a setup, the differences do not necessarily imply that the employees of one function are inferior (or superior) to employees of a different function. Instead, it should be observed as the same stimuli occurring differently and providing us with multiple perspectives on the same task (Snow, 1997). Contrary to this, mindfulness is about an open, single, and undivided observation of anything (e.g., cognitive task) happening either internally or externally, or both. It does emphasize on any specific approach or perspective towards a stimulus (Langer \& Moldoveanu, 2000). Future studies can examine these similar constructs along with mindfulness in order to understand their impact on compulsive SNS use.

There is a growing body of research that shows the linkages between management, spirituality, and religion (Pandey \& Singh, 2019; Pandey \& Varkkey, 2020). Religion and its philosophical routing cannot be ignored in the managerial discourse of present times (Hassan \& Pandey. 2019, Pandey \& Gupta, 2018). The study shows the efficacy of Eastern religious practices like mindfulness in providing solutions to modern-age problems. Psychological capital and contracts provide many such mediating mechanism that can be studied in future studies (Jha, Pandey \& Varkkey, 2018; Pandey, Gupta \& Hassan, 2020). Future studies can look at other religious practices like yoga, prayer and chanting in dealing with modern-day challenges.

\section{References}

Aherne, C., Moran, A. P., \& Lonsdale, C. (2011). The effect of mindfulness training on athletes' flow: An initial investigation. The Sport Psychologist, 25(2), 177-189.

Al-Yafi, K., El-Masri, M., \& Tsai, R. (2018). The effects of using social network sites on academic performance: the case of Qatar. Journal of Enterprise Information Management, 33(3), 446-462.

Andreassen, C. S. (2015). Online social network site addiction: A comprehensive review. Current Addiction Reports, 2(2), 175-184.

Andreassen, C. S., Billieux, J., Griffiths, M. D., Kuss, D. J., Demetrovics, Z., Mazzoni, E., \& Pallesen, S. (2016). The relationship between addictive use of social media and video games and symptoms of psychiatric disorders: A large-scale cross-sectional study. Psychology of Addictive Behaviors, 30(2), 252.

Apaolaza, V., Hartmann, P., D'Souza, C., \& Gilsanz, A. (2019). Mindfulness, Compulsive Mobile Social Media Use, and Derived Stress: The Mediating Roles of Self-Esteem and Social Anxiety. Cyberpsychology, Behavior, and Social Networking, 22(6), 388-396. 
Arora, R., \& Stoner, C. (2009). A mixed method approach to understanding brand personality. Journal of Product and Brand Management, 18(4), 272-283.

Baer, R. A., Smith, G. T., Hopkins, J., Krietemeyer, J., \& Toney, L. (2006). Using self-report assessment methods to explore facets of mindfulness. Assessment, 13(1), 27-45.

Bean, V. (2018). Trait Mindfulness, Facebook Use, Life Satisfaction, and Well-Being (Doctoral dissertation, University of Kansas).

Berman, E. A. (2017). An Exploratory Sequential Mixed Methods Approach to Understanding Researchers' Data Management Practices at UVM: Findings from the Qualitative Phase. Journal of eScience Librarianship, 6(1), 5.

Beyens, I., Frison, E., \& Eggermont, S. (2016). "I don't want to miss a thing": Adolescents' fear of missing out and its relationship to adolescents' social needs, Facebook use, and Facebook related stress. Computers in Human Behavior, 64(1), 1-8.

Bright, L. F., Kleiser, S. B., \& Grau, S. L. (2015). Too much Facebook? An exploratory examination of social media fatigue. Computers in Human Behavior, 44, 148-155.

Brown, K. W., Goodman, R. J., \& Inzlicht, M. (2013). Dispositional mindfulness and the attenuation of neural responses to emotional stimuli. Social cognitive and affective neuroscience, 8(1), 93-99.

Calvete, E., Gámez-Guadix, M., \& Cortazar, N. (2017). Mindfulness facets and problematic Internet use: A six-month longitudinal study. Addictive Behaviors, 72(1), 57-63.

Cameron, R. (2009). A sequential mixed model research design: Design, analytical and display issues. International Journal of Multiple Research Approaches, 3(2), 140-152.

Cao, X., Masood, A., Luqman, A., \& Ali, A. (2018). Excessive use of mobile social networking sites and poor academic performance: Antecedents and consequences from stressorstrain-outcome perspective. Computers in Human Behavior, 85(1), 163-174.

Charoensukmongkol, P. (2013). The contributions of mindfulness meditation on burnout, coping strategy, and job satisfaction: Evidence from Thailand. Journal of Management $\mathcal{E}$ Organization, 19(5), 544-558.

Charoensukmongkol, P. (2016). Mindful Facebooking: The moderating role of mindfulness on the relationship between social media use intensity at work and burnout. Journal of health psychology, 21(9), 1966-1980.

Charoensukmongkol, P., Moqbel, M., \& Gutierrez-Wirsching, S. (2017). Social media sites use intensity and job burnout among the US and Thai employees. International Journal of Cyber Behavior, Psychology and Learning (IJCBPL), 7(1), 34-51.

Chiesa, A., Calati, R., \& Serretti, A. (2011). Does mindfulness training improve cognitive abilities? A systematic review of neuropsychological findings. Clinical Psychology Review, 31(3), 449-464.

Cho, H., Kim, D. J., \& Park, J. W. (2017). Stress and adult smartphone addiction: Mediation by self-control, neuroticism, and extraversion. Stress and Health, 33(5), 624-630.

Coker, L. A., Samuel, D. B., \& Widiger, T. A. (2002). Maladaptive personality functioning within the Big Five and the five-factor model. Journal of Personality Disorders, 16(5), 385401. 
Cook, R. H., Griffiths, M. D., \& Pontes, H. M. (2020). Personality factors in exercise addiction: a pilot study exploring the role of narcissism, extraversion, and agreeableness. International Journal of Mental Health and Addiction, 18(1), 89-102.

Corbin, J., \& Strauss, A. (2014). Basics of qualitative research: Techniques and procedures for developing grounded theory. Sage publications.

Costa Jr, P. T., McCrae, R. R., \& Norris, A. H. (1981). Personal adjustment to aging: Longitudinal prediction from neuroticism and extraversion. Journal of Gerontology, 36(1), 78-85.

Creswell, J. D. (2017). Mindfulness interventions. Annual review of psychology, 68, 491-516.

Crowne, D. P., \& Marlowe, D. (1960). A new scale of social desirability independent of psychopathology. Journal of Consulting Psychology, 24(4), 349.

De Cock, R., Vangeel, J., Klein, A., Minotte, P., Rosas, O., \& Meerkerk, G.-J. (2014). Compulsive use of social networking sites in Belgium: Prevalence, profile, and the role of attitude toward work and school. Cyberpsychology, Behavior, and Social Networking, 17(3), 166-171.

De Vibe, M., Solhaug, I., Tyssen, R., Friborg, O., Rosenvinge, J. H., Sørlie, T., \& Bjørndal, A. (2013). Mindfulness training for stress management: a randomized controlled study of medical and psychology students. BMC Medical Education, 13(1), 107.

Dhir, A., Yossatorn, Y., Kaur, P., \& Chen, S. (2018). Online social media fatigue and psychological wellbeing-A study of compulsive use, fear of missing out, fatigue, anxiety and depression. International Journal of Information Management, 40(1), 141-152.

Ding, L. (2019). Applying gamifications to asynchronous online discussions: A mixed methods study. Computers in Human Behavior, 91(1), 1-11.

Divine, A., Watson, P. M., Baker, S., \& Hall, C. R. (2019). Facebook, relatedness and exercise motivation in university students: a mixed methods investigation. Computers in Human Behavior, 91(1), 138-150.

Draucker, C. B., Martsolf, D. S., Ross, R., \& Rusk, T. B. (2007). Theoretical sampling and category development in grounded theory. Qualitative Health Research, 17(8), 1137-1148.

Fox, J., \& Moreland, J. J. (2015). The dark side of social networking sites: An exploration of the relational and psychological stressors associated with Facebook use and affordances. Computers in human behavior, 45, 168-176.

Fraumeni-McBride, J. (2019). Addiction and Mindfulness; Pornography Addiction and Mindfulness-Based Therapy ACT. Sexual Addiction \& Compulsivity, 26(1-2), 42-53.

Friedman, H. S., \& Schustack, M. W. (2016). Personality: Classic theories and modern research. Pearson. New York.US

Gioia, D. A., Corley, K. G., \& Hamilton, A. L. (2013). Seeking qualitative rigor in inductive research: Notes on the Gioia methodology. Organizational Research Methods, 16(1), 15-31.

Gosling, S. D., Rentfrow, P. J., \& Swann Jr, W. B. (2003). A very brief measure of the Big-Five personality domains. Journal of Research in Personality, 37(6), 504-528.

Griffith, M., \& Kuss, D. (2018, April 25). 6 questions help reveal if you're addicted to social media. Washington Post. Retrieved from https://www.washingtonpost.com/news/theworldpost/wp/2018/04/25/social-mediaaddiction/. 
Gupta, M., Pandey, J., Gaur, J., \& Vohra, N. (2019). Research on Role of Technology in Workforce Management. Australasian Journal of Information Systems, 23, 1-4.

Han, B. (2018). Social media burnout: definition, measurement instrument, and why we care. Journal of Computer Information Systems, 58(2), 122-130.

Hancock, A.-M. (2007). Intersectionality as a normative and empirical paradigm. Politics $\mathcal{E}$ Gender, 3(2), 248.

Hassan, Y., \& Pandey, J. (2019). Examining the engagement of young consumers for religiously sanctioned food: the case of halal food in India. Young Consumers, 21(2), 211232.

Hobfoll, S. E. (1988). The ecology of stress. Washington. DC: Hemisphere.

Hobfoll, S. E., \& Shirom, A. (2000). Conservation of resources theory. Appears in Handbook of Organizational Behavior, RT Golembiewski (Ed.), Marcel Dekker, New York, 57-80.

Hogan, R. (2007). Hogan Personality Inventory. Retrieved from https://www.crownedgrace.com/wp-content/uploads/2016/04/Hogan-PersonalityInventory.pdf

Inceoglu, I., \& Warr, P. (2011). Personality and Job Engagement. Journal of Personnel Psychology, 10(4), 177-181.

Ivankova, N. V, Creswell, J. W., \& Stick, S. L. (2006). Using mixed-methods sequential explanatory design: From theory to practice. Field Methods, 18(1), 3-20.

Jain, S., Shapiro, S. L., Swanick, S., Roesch, S. C., Mills, P. J., Bell, I., \& Schwartz, G. E. R. (2007). A randomized controlled trial of mindfulness meditation versus relaxation training: effects on distress, positive states of mind, rumination, and distraction. Annals of Behavioral Medicine, 33(1), 11-21.

Jha, J., Pandey, J., \& Varkkey, B. (2019). Examining the role of perceived investment in employees' development on work-engagement of liquid knowledge workers: Moderating effects of psychological contract. Journal of Global Operations and Strategic Sourcing, 12(2), 225-245.

Johns, G. (2018). Advances in the treatment of context in organizational research. Annual Review of Organizational Psychology and Organizational Behavior, 5(1), 21-46.

Karing, C., \& Beelmann, A. (2019). Cognitive Emotional Regulation Strategies: Potential Mediators in the Relationship Between Mindfulness, Emotional Exhaustion, and Satisfaction?. Mindfulness, 10(3), 459-468.

Kiberd, R. (2018, August 18). No Ti. The Guardian. Retrieved from https://www.theguardian.com/commentisfree/2019/mar/19/social-media-facebookaddiction-not-natural-normal-disease.

Kim, J., LaRose, R., \& Peng, W. (2009). Loneliness as the cause and the effect of problematic Internet use: The relationship between Internet use and psychological well-being. Cyberpsychology \& behavior, 12(4), 451-455.

Kim, Y., Hsu, S.-H., \& de Zúñiga, H. G. (2013). Influence of social media use on discussion network heterogeneity and civic engagement: The moderating role of personality traits. Journal of Communication, 63(3), 498-516. 
Klobas, J. E., McGill, T. J., Moghavvemi, S., \& Paramanathan, T. (2018). Compulsive YouTube usage: A comparison of use motivation and personality effects. Computers in Human Behavior, 87(1), 129-139.

Kumar, R., Sachan, A., \& Mukherjee, A. (2017). Qualitative approach to determine user experience of e-government services. Computers in Human Behavior, 71(1), 299-306.

Lai, H. M., Hsieh, P. J., \& Zhang, R. C. (2019). Understanding adolescent students' use of Facebook and their subjective wellbeing: a gender-based comparison. Behaviour $\mathcal{E}$ Information Technology, 38(5), 533-548.

Lam, L. W. (2012). Impact of competitiveness on salespeople's commitment and performance. Journal of Business Research, 65(9), 1328-1334.

Langley, A. (1999). Strategies for theorizing from process data. Academy of Management Review, 24(4), 691-710.

LaRose, R., Lin, C. A., \& Eastin, M. S. (2003). Unregulated Internet usage: Addiction, habit, or deficient self-regulation? Media Psychology, 5(3), 225-253.

Lavrakas, P. J. (2008). Encyclopedia of survey research methods. Sage Publications.

Lee, K.-T., Noh, M.-J., \& Koo, D.-M. (2013). Lonely people are no longer lonely on social networking sites: The mediating role of self-disclosure and social support. Cyberpsychology, Behavior, and Social Networking, 16(6), 413-418.

Lee, Y.-K., Chang, C.-T., Lin, Y., \& Cheng, Z.-H. (2014). The dark side of smartphone usage: Psychological traits, compulsive behavior and technostress. Computers in Human Behavior, 31(1), 373-383.

Li, L., Worch, E., Zhou, Y., \& Aguiton, R. (2015). How and why digital generation teachers use technology in the classroom: An explanatory sequential mixed methods study. International Journal for the Scholarship of Teaching and Learning, 9(2), 2.

Liao, F.-Y., Yang, L.-Q., Wang, M., Drown, D., \& Shi, J. (2013). Team-member exchange and work engagement: Does personality make a difference? Journal of Business and Psychology, 28(1), 63-77.

Liu, C., \& Ma, J. (2018). Social media addiction and burnout: The mediating roles of envy and social media use anxiety. Current Psychology, 1-9.

Longstreet, P., \& Brooks, S. (2017). Life satisfaction: A key to managing Internet \& social media addiction. Technology in Society, 50, 73-77.

Luqman, A., Masood, A., Weng, Q., Ali, A., \& Rasheed, M. I. (2020). Linking Excessive SNS Use, Technological Friction, Strain, and Discontinuance: The Moderating Role of Guilt. Information Systems Management, 37(2), 94-112.

MacPhail, C., Khoza, N., Abler, L., \& Ranganathan, M. (2016). Process guidelines for establishing intercoder reliability in qualitative studies. Qualitative Research, 16(2), 198212.

Mao, J. (2014). Social media for learning: A mixed methods study on high school students' technology affordances and perspectives. Computers in Human Behavior, 33, 213-223.

Masood, A., Feng, Y., Luqman, A., \& Ali, A. (2020). Adverse consequences of excessive social networking site use on academic performance: Explaining underlying mechanism from stress perspective. Computers in Human Behavior, 106476. 
McCord, M. A., Joseph, D. L., \& Grijalva, E. (2014). Blinded by the light: The dark side of traditionally desirable personality traits. Industrial and Organizational Psychology, 7(1), 130-137.

McIntyre, E., Wiener, K. K., \& Saliba, A. J. (2015). Compulsive Internet use and relations between social connectedness, and introversion. Computers in Human Behavior, 48, 569574 .

Meerkerk, G. J., van den Eijnden, R. J., Franken, I. H. A., \& Garretsen, H. F. L. (2010). Is compulsive internet use related to sensitivity to reward and punishment, and impulsivity?. Computers in human behavior, 26(4), 729-735.

Nalwa, K., \& Anand, A. P. (2003). Internet addiction in students: A cause of concern. Cyberpsychology \& Behavior, 6(6), 653-656.

Nawaz, M. A., Shah, Z., Nawaz, A., Asmi, F., Hassan, Z., \& Raza, J. (2018). Overload and exhaustion: Classifying SNS discontinuance intentions. Cogent Psychology, 5(1), 1515584.

Ong, E. Y. L., Ang, R. P., Ho, J. C. M., Lim, J. C. Y., Goh, D. H., Lee, C. S., \& Chua, A. Y. K. (2011). Narcissism, extraversion and adolescents' self-presentation on Facebook. Personality and Individual Differences, 50(2), 180-185.

Palinkas, L. A., Horwitz, S. M., Green, C. A., Wisdom, J. P., Duan, N., \& Hoagwood, K. (2015). Purposeful sampling for qualitative data collection and analysis in mixed method implementation research. Administration and Policy in Mental Health and Mental Health Services Research, 42(5), 533-544.

Pandey, J., \& Gupta, M. (2019). Religion in the lives of Hindu widows: Narratives from Vrindavan, India. Psychology of Religion and Spirituality, 11(2), 91-100.

Pandey, J., Gupta, M., \& Hassan, Y. (2020). Intrapreneurship to Engage Employees: Role of Psychological Capital. Management Decision. https://doi.org/10.1108/MD-06-2019-0825

Pandey, J., \& Varkkey, B. (2017). Impact of Religion-Based Caste System on the Dynamics of Indian Trade Unions: Evidence from Two State-Owned Organizations in North India. Business \& Society, 59(5), 995-1034.

Pandey, J., \& Singh, M. (2019). Positive Religious Coping as a Mechanism for Enhancing Job Satisfaction and Reducing Work-family Conflict: A Moderated Mediation Analysis. Journal of Management, Spirituality \& Religion, 16(3), 314-339.

Pandey, J., \& Sohani, S. S. (2020). Engaging Stakeholders of Crowdsourced Work: Case of Cab Aggregators of India. Journal of Electronic Commerce in Organizations., 18(3), 38-52.

Pantic, I. (2014). Online social networking and mental health. Cyberpsychology, Behavior, and Social Networking, 17(10), 652-657.

Park, H. I., Jacob, A. C., Wagner, S. H., \& Baiden, M. (2014). Job control and burnout: A metaanalytic test of the Conservation of Resources model. Applied Psychology, 63(4), 607-642.

Quan-Haase, A. (2007). University students' local and distant social ties: Using and integrating modes of communication on campus. Information, Communication $\mathcal{E}$ Society, 10(5), 671693.

Reb, J., Narayanan, J., \& Chaturvedi, S. (2014). Leading mindfully: Two studies on the influence of supervisor trait mindfulness on employee wellbeing and performance. Mindfulness, 5(1), 36-45. 
Rhodewalt, F., \& Tragakis, M. W. (2003). Self-esteem and self-regulation: Toward optimal studies of self-esteem. Psychological Inquiry, 14(1), 66-70.

Roccas, S., Sagiv, L., Schwartz, S. H., \& Knafo, A. (2002). The big five personality factors and personal values. Personality and Social Psychology Bulletin, 28(6), 789-801.

Ryan, T., Chester, A., Reece, J., \& Xenos, S. (2014). The uses and abuses of Facebook: A review of Facebook addiction. Journal of Behavioral Addictions, 3(3), 133-148.

Rybak, C. (2013). Nurturing positive mental health: Mindfulness for wellbeing in counseling. International Journal for the Advancement of Counselling, 35(2), 110-119.

Salanova, M., Llorens, S., \& Cifre, E. (2013). The dark side of technologies: Technostress among users of information and communication technologies. International Journal of Psychology, 48(3), 422-436.

Sharif, S. P., \& Khanekharab, J. (2017). Identity confusion and materialism mediate the relationship between excessive social network site usage and online compulsive buying. Cyberpsychology, Behavior, and Social Networking, 20(8), 494-500.

Shonin, E., Van Gordon, W., \& Griffiths, M. D. (2016). Mindfulness and wellbeing: Towards a unified operational approach. In I. Ivtzan \& T. Lomas (Eds.), Mindfulness in positive psychology: The science of meditation and wellbeing (p. 280-292). Oxford: Routledge.

Singletary, S. (n.d.). Is social media destroying humankind? TedX Sydney. Retrieved from https://tedxsydney.com/idea/is-social-media-destroying-humankind/

Slater, D. (2002). Social relationships and identity online and offline. Handbook of New Media: Social Shaping and Consequences of ICTs, 533-546.

Spears, C. A., Hedeker, D., Li, L., Wu, C., Anderson, N. K., Houchins, S. C., Cinciripini, P. M. (2017). Mechanisms underlying mindfulness-based addiction treatment versus cognitive behavioral therapy and usual care for smoking cessation. Journal of Consulting and Clinical Psychology, 85(11), 1029.

Srivastava, S. C., \& Chandra, S. (2018). Social presence in virtual world collaboration: An uncertainty reduction perspective using a mixed methods approach. MIS Quarterly, 42(3), 779-804.

Sriwilai, K., \& Charoensukmongkol, P. (2016). Face it, don't Facebook it: impacts of social media addiction on mindfulness, coping strategies and the consequence on emotional exhaustion. Stress and Health, 32(4), 427-434.

Taber, K. S. (2018). The use of Cronbach's alpha when developing and reporting research instruments in science education. Research in Science Education, 48(6), 1273-1296.

Tashakkori, A., \& Teddlie, C. (2010). Sage handbook of mixed methods in social \& behavioral research. Sage.

Throuvala, M. A., Griffiths, M. D., Rennoldson, M., \& Kuss, D. J. (2019). Motivational processes and dysfunctional mechanisms of social media use among adolescents: A qualitative focus group study. Computers in Human Behavior, 93, 164-175.

Turel, O., \& Osatuyi, B. (2017). A peer-influence perspective on compulsive social networking site use: Trait mindfulness as a double-edged sword. Computers in Human Behavior, 77, 47-53. 
Von Hellens, L., Beekhuyzen, J., \& Kerr, D. (2006). Qualitative research in information systems. Australasian Journal of Information Systems, 13(2).

Waters, R. D., Burnett, E., Lamm, A., \& Lucas, J. (2009). Engaging stakeholders through social networking: How nonprofit organizations are using Facebook. Public Relations Review, 35(2), 102-106.

Watson, D., \& Clark, L. A. (1997). Extraversion and its positive emotional core. In Handbook of personality psychology (pp. 767-793). Elsevier.

Weinstein, N., Brown, K. W., \& Ryan, R. M. (2009). A multi-method examination of the effects of mindfulness on stress attribution, coping, and emotional wellbeing. Journal of research in personality, 43(3), 374-385.

WHO. (2018, September 13). Public health implications of excessive use of the Internet and other communication and gaming platforms. Geneva. Retrieved from https://www.who.int/news-room/detail/13-09-2018-public-health-implications-ofexcessive-use-of-the-internet-and-other-communication-and-gamingplatformshttps://www.who.int/news-room/detail/13-09-2018-public-healthimplications-of-excessive-use-of-the-internet-and-other-communication-and-gamingplatforms

Wiegner, L., Hange, D., Björkelund, C., \& Ahlborg, G. (2015). Prevalence of perceived stress and associations to symptoms of exhaustion, depression and anxiety in a working age population seeking primary care-an observational study. BMC Family Practice, 16(1), 18.

Witt, L. A. (2002). The interactive effects of extraversion and conscientiousness on performance. Journal of Management, 28(6), 835-851.

Wright, T. A., \& Cropanzano, R. (1998). Emotional exhaustion as a predictor of job performance and voluntary turnover. Journal of Applied Psychology, 83(3), 486.

Zhang, S., Kwok, R. C.-W., Lowry, P. B., Liu, Z., \& Wu, J. (2019). The influence of role stress on self-disclosure on social networking sites: A conservation of resources perspective. Information \& Management, 56(7), 103147.

Zhang, Y., Tang, L. S. T., \& Leung, L. (2011). Gratifications, collective self-esteem, online emotional openness, and traitlike communication apprehension as predictors of Facebook uses. Cyberpsychology, Behavior, and Social Networking, 14(12), 733-739.

Zheng, X., \& Lee, M. K. O. (2016). Excessive use of mobile social networking sites: Negative consequences on individuals. Computers in Human Behavior, 65, 65-76. 


\section{Appendix 1}

\section{Measurement scales used for different constructs in the study.}

\begin{tabular}{|c|c|c|l|}
\hline Name of the construct & Scale used & No of items & \multicolumn{1}{c|}{ Sample item } \\
\hline Compulsive SNS use & Turel \& Osatuyi (2017) & 7 & $\begin{array}{l}\text { I spent time on social networking sites even } \\
\text { though I had other deadlines }\end{array}$ \\
\hline Mindfulness & Baer et al. (2006) & 6 & $\begin{array}{l}\text { It seems I am "running on automatic" } \\
\text { without much awareness of what I'm } \\
\text { Doing. }\end{array}$ \\
\hline Emotional Exhaustion & Han (2018) & 3 & $\begin{array}{l}\text { I feel exhausted by using social networking } \\
\text { sites. }\end{array}$ \\
\hline Extraversion & Gosling et al. (2003) & 2 & $\begin{array}{l}\text { I see myself as extraverted, enthusiastic. } \\
\text { Social desirability }\end{array}$ \\
\hline
\end{tabular}

Copyright: (C) 2021 Hassan \& Pandey. This is an open-access article distributed under the terms of the Creative Commons Attribution-NonCommercial 3.0 Australia License, which permits non-commercial use, distribution, and reproduction in any medium, provided the original author and AJIS are credited.

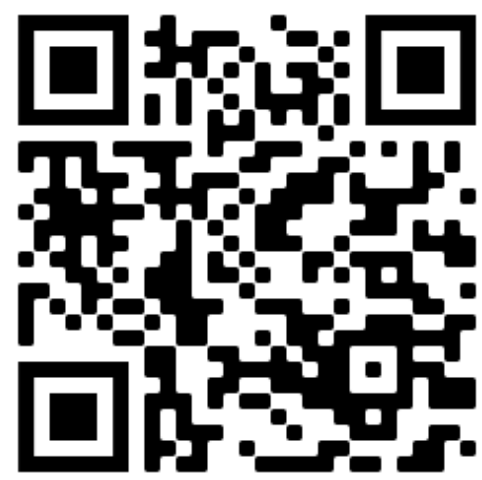

